GUSTAVO DE CARVALHO MARIN

VERIFICAÇÃO DA PROPORCIONALIDADE NA INTERPRETAÇÃO

DO DIREITO PENAL: análise da aplicação pelo Supremo Tribunal

Federal entre 2011-2012

Dissertação de Mestrado

Orientador: Prof. Dr. Eduardo Saad-Diniz

UNIVERSIDADE DE SÃO PAULO

FACULDADE DE DIREITO

São Paulo-SP

2015 


\title{
VERIFICAÇÃO DA PROPORCIONALIDADE NA INTERPRETAÇÃO DO DIREITO PENAL: análise da aplicação pelo Supremo Tribunal
} Federal entre 2011-2012

\begin{abstract}
Dissertação de Mestrado apresentada à Banca Examinadora do Programa de Pós-Graduação em Direito, da Faculdade de Direito da Universidade de São Paulo, como exigência parcial para obtenção do título de Mestre em Direito, na área de concentração Direito Penal, sob orientação do Prof. Dr. Eduardo Saad-Diniz.
\end{abstract}

UNIVERSIDADE DE SÃO PAULO

FACULDADE DE DIREITO

São Paulo-SP 
MARIN, Gustavo de Carvalho.

Verificação da proporcionalidade na interpretação do direito penal: análise da aplicação pelo Supremo Tribunal Federal entre 2011-2012. São Paulo-SP, 2015.

264 p.; $30 \mathrm{~cm}$

Dissertação de Mestrado apresentada à Faculdade de Direito da Universidade de São Paulo

Orientador: Prof. Dr. Eduardo Saad-Diniz.

1. Direito. 2. Penal. 3. Proporcionalidade. 4. Ponderação. 5. Supremo Tribunal Federal 


\section{Agradecimentos}

Agradeço ao Geraldo Magela, Rita de Cássia, Oscar de Carvalho, Neninha, Maria Aparecida, José Melo, Carlos Junior, Fernanda, João Marin e Marivalda, por constituírem o pilar de sustentação emocional tão necessário em períodos de tensão, e também por multiplicarem as alegrias por meio da partilha. Sara Tironi, muito obrigado pela linda companhia de todos os momentos, pela indescritível ajuda nestes últimos dias decisivos e por todo o carinho,

Ao Prof. Dr. Eduardo Saad-Diniz, por conseguir aliar a seriedade do respeito acadêmico à leveza que apenas as amizades sinceras são capazes de proporcionar.

Ao Thales Coelho, Rafael Nardi e Gustavo Mascarenhas, companheiros penalistas de primeira viagem. Ao César Augusto Moreira, amigo e para sempre mestre. Ao Renato, Décio, Nidival e Maria Cláudia, pela amizade criada em salas de aula e cafés. À Camila Salles, Ana Cristina, Nathalia Regina e Jéssica Sponchiado, por compartilharem suas vidas acadêmicas comigo e por me ensinarem tanto. Ao Alex Rodrigues e Milton Junior, por serem os amigos que sempre esperam de braços abertos, independentemente das ausências.

À Faculdade de Direito de Ribeirão Preto da USP e a todas as amizades originadas naqueles corredores, dos quais provavelmente jamais conseguirei sair em sentimento. À Universidade de Sevilha, pelo acolhimento, em especial à Professora Teresa Aguado Correa e Miguel Polaino-Orts, bem como aos amigos Alri, Silvia, Henrique e Pepe. Ao Max Planck Institute, pela oportunidade de utilizar a incomparável estrutura. Ao Instituto Brasileiro de Ciências Criminais e à Universidade de São Paulo, especialmente aos Professores Alamiro Velludo Salvador Netto e Mariângela Gama de Magalhães Gomes, pelas críticas e sugestões no exame de qualificação. Ao Eduardo Gaban e equipe, pela compreensão e paciência na reta final.

A todos aqueles que guardo no coração e que tanto me ajudaram neste período, ainda que sem saber. 


\section{RESUMO}

MARIN, Gustavo de Carvalho. Verificação da proporcionalidade na interpretação do direito penal: análise da aplicação pelo Supremo Tribunal Federal entre 2011-2012. Dissertação. Faculdade de Direito, Universidade de São Paulo, São Paulo, 2015.

A pesquisa aborda os aspectos positivos $\mathrm{e}$ as debilidades das teorias da proporcionalidade, analisando o diálogo entre as interpretações doutrinárias constitucionalista e penalista quanto ao tema. Tendo como base um contexto social marcado pelo recrudescimento do poder punitivo, por distorções na tensão liberdade-segurança e pela abertura do sistema jurídico a influxos de seu entorno, o trabalho busca identificar o papel da proporcionalidade em sentido amplo na estabilização normativa envolvendo as relações jurídicas conflituosas em direito penal. Tendo como hipótese de investigação a ideia de que a proporcionalidade é utilizada frequentemente como artifício retórico nominalista, servindo nas argumentações jurídicas tanto à limitação quanto à justificação das intervenções punitivas, a pesquisa se dedica a testar tal afirmação preliminar por meio de dois estágios de análise: (i) primeiramente, é desenvolvido um arcabouço teórico que possibilita que discute o conteúdo dogmático das regras de proporcionalidade e sua funcionalidade na interpretação penal, buscando com isso viabilizar a (ii) verificação empírica e crítica do sentido normativo atribuído pelo Supremo Tribunal Federal à proporcionalidade no direito penal nos anos de 2011 e 2012.

Palavras-chave: Direito penal; Constituição; Proporcionalidade; Interpretação; Supremo Tribunal Federal. 


\begin{abstract}
MARIN, Gustavo de Carvalho. Verificação da proporcionalidade na interpretação do direito penal: análise da aplicação pelo Supremo Tribunal Federal entre 2011-2012. Dissertação. Faculdade de Direito, Universidade de São Paulo, São Paulo, 2015.
\end{abstract}

The research addresses the strengths and weaknesses of the proportionality theories through a dialogue between constitutional and criminal legal studies. The investigation aims at identifying the proportionality role in the stabilization of normative standards related to conflicting relations concerning criminal law, within the context of the increasing of the punitive power, of distortions regarding the tension between liberty-security and of the legal system's opening to the expansive flows deriving from law's environment. The research hypothesis is that proportionality is frequently used within legal discussions as a nominalist and rhetorical resource, contributing to both the limitation and the justification of state penal measures. Therefore, the investigation tests such fundamental preliminary statement through two analytical stages: (i) first, the research develops a theoretical framework, which allows the discussion of the dogmatic contents of the proportionality rules and its functionality concerning criminal law interpretation. As a result of the first stage, the research performs (ii) an empirical verification and critical evaluation of the normative sense assigned by the Brazil's Supreme Court to the proportionality within criminal law cases among 2011 and 2012.

Keywords: Criminal Law; Constitution; Proportionality; Interpretation; Supreme Court. 


\section{SUMÁRIO}

\section{INTRODUÇÃO}

\section{CONSTITUIÇÃO, DIREITO PENAL E O PROBLEMA DA PROPORCIONALIDADE DAS}

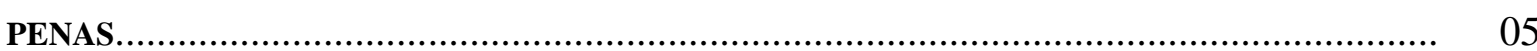

1.1 Constituição como acoplamento estrutural entre direito e política....................... 05

1.2 Vínculos possíveis entre Constituição e direito penal: propostas para uma releitura.

1.3 Corrupção do sistema pelo entorno: sistema jurídico-penal e a tensão liberdade-segurança.

1.4 Interpretação judicial do direito penal em sociedades complexas e o problema da proporcionalidade

2 A PROPORCIONALIDADE DA PENAS.

2.1 Uma distinção necessária.

2.2 Filosofia da punição e a exigência de correspondência gradativa entre comportamento e pena.

2.2.1 Os "reformadores"

2.2.2 Pena e o imperativo categórico de Kant.

2.2.3 Hegel e a pena proporcional como instrumento de subjetivação...... 75

2.2.4 Proporcionalidade penal como princípio de justiça?

2.3 Conteúdo material da proporcionalidade abstrata e concreta das penas. 98

\section{PROPORCIONALIDADE EM SENTIDO AMPLO}

3.1 A proporcionalidade das penas e a proporcionalidade em sentido amplo

3.2 Proporcionalidade em sentido amplo e noções instrumentalistas do direito

3.3 Natureza normativa da proporcionalidade em sentido amplo.

3.4 Função e conteúdo das regras de proporcionalidade.

3.4.1 Idoneidade. 141

3.4.2 Necessidade. 151

3.4.3 Proporcionalidade em sentido estrito. 160

3.5 Algumas críticas à proporcionalidade e à técnica da ponderação. 177

3.5.1 Crítica de Matthias Jestaedt.

3.5.2 Marcelo Neves: colisão de discursos no sistema jurídico, crítica à ponderação otimizante e os riscos da "compulsão ponderadora" .

3.5.3 A crítica penalista: proporcionalidade como instrumento de limitação ou de legitimação formal de criminalizações? 


\section{A INTERPRETAÇÃO DO DIREITO PENAL POR MEIO DA PROPORCIONALIDADE: OBSERVAÇÃO DO COMPORTAMENTO DECISÓRIO DO SUPREMO TRIBUNAL}

\section{FEDERAL}

4.1 A importância da análise empírica.............................................................. 188

4.2 Método a ser empregado na observação......................................................... 193

4.3 Análise quantitativa da jurisprudência no biênio 2011-2012 ............................ 201

4.3.1 Sentido conferido à proporcionalidade ..................................................... 201

4.3.2 Aplicação da proporcionalidade: entre regra sistemática e mera referência argumentativa................................................................................ 205

4.3.3 Resultado da aplicação da proporcionalidade: entre a limitação e a justificação da intervenção jurídico-penal....................................................... 207

4.4 Análise qualitativa: principais linhas de entendimento do STF em torno da proporcionalidade no biênio 2011-2012 .......................................................... 212

4.4.1 Insignific ância........................................................................................ 212

4.4.2 Penas alternativas e regime de cumprimento de pena: proibições legislativas "absolutas e apriorísticas" .............................................................. 216

4.4.3 Violência doméstica e discriminação positiva............................................ 218

4.4.4 Crimes de perigo abstrato: porte ilegal de arma de fogo desmuniciada.... 223

4.4.5 Ponderação de direitos e a antecipação terapêutica do parto em casos de

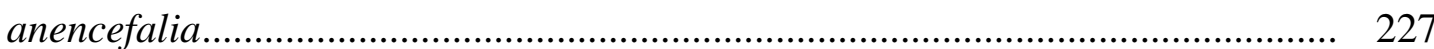

4.5 Há um modelo de proporcionalidade adotado pelo Supremo Tribunal Federal nos conflitos jurídico-penais? ....................................................................... 231

CONCLUSÃO

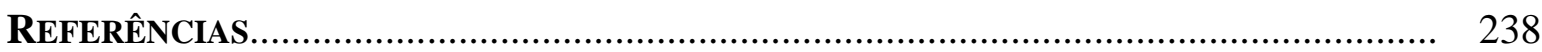




\section{INTRODUÇÃO}

Em um cenário jurídico-social caracterizado por movimentos de recrudescimento punitivo, decorrentes de uma exasperação distorcida da tensão liberdade-segurança e de uma influência demasiada de lógicas próprias de sistemas sociais expansivos em decisões que deveriam seguir uma racionalidade mais propriamente jurídica, a proporcionalidade ocupa uma posição de destaque enquanto potencial limite constitucional ao poder de punir. O exame de proporcionalidade em sentido amplo, composto pelas máximas de adequação, necessidade e proporcionalidade em sentido estrito, fornece critérios interpretativos aptos à verificação da procedência constitucional de intervenções jurídico-penais em direitos fundamentais, ganhando capacidade de rendimento tanto nas categorias da teoria do delito quanto nas questões situadas no âmbito da teoria da pena.

A controvérsia surge, no entanto, diante de percepções segundo as quais a proporcionalidade em sentido amplo conteria debilidades estruturais e estaria inserida em um contexto teórico capaz de comprometer a própria funcionalidade das interações entre a ordem jurídico-constitucional e infraconstitucional. Em circunstâncias sociais de maleabilidade das decisões jurídicas em decorrência de influxos de comunicações e programas próprios a outros sistemas que não o jurídico, não parece claro o papel que a proporcionalidade realmente desempenhar nas argumentações e decisões jurídico-penais com impactos restritivos sobre direitos fundamentais. Lançam-se questionamentos sobre as potencialidades das constituições de sensibilizar o exercício do poder punitivo, ou ao menos qual seu alcance na conformação do direito penal em uma sociedade caracterizada pelo dissenso no cerne da esfera pública, o que atinge a delimitação de conteúdo dos deveres penais e constitucionais, bem como da efetiva relação entre estes.

Neste sentido, o teste de proporcionalidade perderia sua funcionalidade enquanto mecanismo de balizamento do poder punitivo: seja porque a dogmática constitucional possui distinções marcantes com relação à penal, ou então porque o exame de proporcionalidade teria como efeito colateral perverso a justificação formal de criminalizações que talvez não resistissem se os tribunais aplicassem interpretações mais próximas das teorias penalistas. Em

contextos de contaminação de sistemas por outros sistemas sociais expansivos, a proporcionalidade parece desempenhar um papel fundamentalmente diferente do que faria se 
operasse em um sistema jurídico com fronteiras sólidas e menos suscetível aos influxos do entorno.

É neste contexto que a pesquisa busca inserir a discussão acerca das teorias da proporcionalidade, com isso tentando demarcar o lugar desta na interpetação penal no contexto dos tribunais, compreendidos enquanto instâncias comunicativas que ocupam o centro do sistema jurídico e são os principais responsáveis pela realização dos testes de proporcionalidade daqueles atos estatais de constitucionalidade indefinida. Recorrendo a uma investigação teórica que conjuga as perspectivas penalistas e constitucionalistas sobre o tema, a pesquisa buscou consolidar um arcabouço crítico que permitisse avançar a um segundo estágio: a observação empírica da movimentação da proporcionalidade nas argumentações dos Ministros do Supremo Tribunal Federal, nos casos de direito penal material julgados pela corte nos anos de 2011 e 2012. A pesquisa trabalha com a hipótesse de que a proporcionalidade é utilizada principalmente como artifício retórico na argumentação jurídica, e que serve tanto à limitação quanto à justificação do poder punitivo - formulação preliminar discutida nas investigações teóricas e empiricamente verificada na análise crítico-reflexiva dos acórdãos que compuseram a amostra estudada.

Buscar um modelo teórico capaz de explicar este contexto jurídico-social complexo, e ao mesmo tempo problemático, mostrou-se de primeira relevância para compreender o papel do Poder Judiciário na interpretação do direito penal, assim como os perigos e as potencialidades do uso da proporcionalidade neste processo. A isso se dedica o Capítulo 1 ("Direito penal, constituição e o problema da proporcionalidade"), voltado ao estabelecimento dos vínculos possíveis entre constituição e direito penal, recorrendo à interpretação sociológica como forma de verificar a variabilidade destas relações conforme as configurações sociais concretas. A pesquisa prossegue também no primeiro capítulo abordando como a interpretação jurídica realizada pelo Poder Judiciário se insere neste contexto, e quais seus impactos sobre a conformação de sistemas jurídico-penais situados em sociedades de alta complxidade. Todo este recurso teórico é empregado para culminar em um início de delimitação do lugar ocupado pela proporcionalidade neste vínculo (socialmente situado) entre direito penal e constituição, de modo ambivalente transitando entre $(i)$ a ampliação e a restrição de direitos; ou entre (ii) ora como mecanismo apto a conter as comunicações expansivas do entorno do sistema jurídico, ora como instrumento de abertura a estes influxos desdiferenciadores. 
O segundo capítulo (“A proporcionalidade das penas”) estabelece a diferença entre, de um lado, a proporcionalidade compreendida como a relação de congruência entre delito e pena, de modo a demarcar suas diferenças em comparação com a outra noção de proporcionalidade enquanto regra de interpretação que comporta um juízo de meio e fim e um balanço de custos e benefícios, teste pelo qual devem passar as justificativas do Estado para a restrição de direitos fundamentais (fundamento prospectivo). Isso servirá primeiramente para delimitar que o núcleo dos estudos aqui realizados reside primordialmente no segundo dos sentidos elencados. Entretanto, esta diferenciação se mostra fundamental também para, no momento em que for observado o comportamento decisório do Supremo Tribunal Federal (STF), poder ser identificado qual das duas formas de compreensão da proporcionalidade está sendo utilizada pela Corte.

Já o terceiro capítulo ("Proporcionalidade em sentido amplo") se destina a fixar as bases dogmáticas do conteúdo das regras de proporcionalidade, de modo a especificar os critérios que as tornam úteis para realizar uma estabilização normativa, mediando as distintas expectativas sociais acerca do direito penal. Este, por sua vez, enfrenta situações diversas de direitos fundamentais abstrata e concretamente colidentes, e também lida com finalidades a serem perseguidas - terrenos férteis ao desenvolvimento de interpretações com base na proporcionalidade. Isso será realizado expondo ainda as críticas especialmente à técnica da ponderação, mediante um cotejo entre as proposições constitucionalistas e penalistas a respeito da temática. Busca-se com isso tanto evidenciar os pontos de dissenso como os de convergência entre as duas perspectivas, objetivando uma maior coerência do marco teórico trabalhado. A natureza normativa da proporcionalidade, assim como o conteúdo e as controvérsias envolvendo suas máximas parciais (idoneidade, necessidade e proporcionalidade em sentido estrito) constituem os assuntos centrais do capítulo, com especial atenção sobre (i) como elas operam na absorção judicial do dissenso estrutural da esfera pública, e (ii) quais algumas das principais críticas doutrinárias que lhe são lançadas.

No quarto e último capítulo (“A interpretação do direito penal por meio da proporcionalidade: observação do comportamento decisório do Supremo Tribunal Federal") é realizada a verificação empírica do comportamento decisório dos Ministros do STF na utilização do critério da proporcionalidade para solucionar casos de direito penal material, realizando o teste da hipótese de investigação. Após explicações de natureza metodológica, é realizada uma pesquisa quantitativa, na qual se espera identificar principalmente: $(i)$ de que maneira o STF compreende primordialmente a proporcionalidade no campo penal, se como 
correlação gradativa entre comportamento e pena ou se como um critério mais amplo de intervenção de medidas estatais restritivas de direitos fundamentais; (ii) de que maneira se dá a aplicação da proporcionalidade, compreendida na segunda e mais ampla acepção: se de maneira sistemática (discriminando sua estrutura dogmática e realizando o teste de proporcionalidade conforme cada máxima parcial) ou nominalista, como mero reforço retórico com outros argumentos articulados; e (iii) se a proporcionalidade, nestes casos, foi utilizada para justificar decisões voltadas à contenção ou justificação da medida punitiva. Em seguida, a pesquisa conta com uma análise qualitativa dos acórdãos, na qual se procura descrever as principais linhas argumentativas presentes na argumentações dos Ministros a respeito da proporcionalidade, utilizando-se para tanto de uma divisão temática de acordo com o problema doutrinário enfrentado pela decisão. Por fim, é feita uma interpretação crítico-reflexiva dos dados coletados nas análises quantitativa e qualitativa, em um esforço no sentido de delimitar um modelo de proporcionalidade possivelmente adotado pelo Supremo Tribunal Federal e expor suas aporias e eventuais vantagens.

Espera-se, ao final, que a pesquisa tenha como resultado uma compreensão das vantagens e debilidades que a proporcionalidade enseja nas movimentações interpretativas dos conflitos jurídico-penais, tendo como enfoque especial um diálogo com a realidade penal e constitucional brasileira, por meio de considerações descritivas e crítico-reflexivas. 


\section{Conclusão}

A partir do estudo das teorias da proporcionalidade na interpretação penal conjugando as perspectivas constitucionalistas e penalistas -, bem como da observação do comportamento decisório dos Ministros do Supremo Tribunal Federal entre 2011 e 2012 nos casos em que a proporcionalidade foi por eles utilizada para interpretar conflitos jurídicopenais, foram alcançados os seguintes resultados principais:

1. Sob uma perspectiva teórico-sistêmica, a afirmação da autorreferencialidade do direito enquanto sistema social autopoiético afasta as concepções que o legitimam com base em instâncias imanentes; ganhando força, por outro lado, discussões a respeito da base de legitimação de um sistema jurídico contingente e permanentemente mutável. Enquanto as teorias de Habermas relacionam a legitimidade decisória intrinsecamente à construção de discursos racionais inseridos em procedimentos participativos moralmente justificáveis, a teoria dos sistemas de Luhmann propõe uma "legitimação pelo procedimento" interna ao próprio sistema jurídico, conclusão em grande medida decorrente do movimento de positivação do direito e das teses luhmannianas no sentido de sua neutralização moral. A pesquisa encontrou solução ao problema nas originais teses de Marcelo Neves, das quais foram extraídos fundamentos de elevada capacidade explicativa da mediação das tensões normativas no direito penal por meio da proporcionalidade. Segundo tal autor, o movimento de positivação conduziu o sistema jurídico a uma "pretensão de autofundamentação constitucional". A constituição, por um lado, é compreendida na teoria dos sistemas como acoplamento estrutural entre direito e política, operando enquanto mecanismo de limitação das zonas de contato entre os dois subsistemas, mas também permitindo a intensificação de uma irritabilidade recíproca. Por outro lado, é concebida também como "estrutura fundante" do sistema jurídico, por meio da qual este reage sobre si mesmo.

2. Daí fazer sentido a delimitação de uma assimetria entre normas constitucionais e infraconstitucionais, lastreada na ideia não de uma hierarquia linear, mas entrelaçada. Da constituição não decorre uma política criminal unívoca: o sentido normativo dos preceitos constitucionais depende das comunicações oriundas da política e dos processos de concretização normativa efetivados por intérpretes-aplicadores, ambas as instâncias comunicativas atuando na delimitação semântica das normas constitucionais por meio da 
seleção de expectativas normativas, assim determinando também o grau de influência da ordem constitucional sobre a conformação do direito penal.

3. O estudo dos complexos processos de atribuição de sentido das normas constitucionais por meio da seleção de expectativas recorrentemente controversas permitiu a exposição dos riscos de se adotar uma teoria penalista fundamentada na constituição, especialmente esperando que deste recurso decorram mecanismos de contenção do poder punitivo. Disso se conclui que a própria amplitude e variabilidade semântica dos preceitos constitucionais permitem interpretações jurídico-penais fundamentalmente diversas e por vezes contrapostas. Isso, aliado ao caráter simbólico das normas de direito fundamental e à constatação de diversos mandamentos de criminalização no material constitucional, explicita as aporias e os riscos de se fundamentar o direito penal em preceitos de política criminal com lastro em uma tão ampla moldura constitucional.

4. A definição da constituição como fonte de um programa político-criminal apriorístico, desta forma, mostra-se não só incompatível com a diferenciação funcional da sociedade, com o dissenso estrutural da esfera pública e com as profundas controvérsias interpretativas em torno do preenchimento dos deveres jurídico-constitucionais e penais. Além disso, carrega consigo a debilidade de buscar programas rígidos e mecanismos de restrição à repressividade em um material francamente controverso e altamente criminalizador, produzindo riscos de desdiferenciação revelados especialmente em contextos nos quais o direito penal tem se escancara à entrada indiscriminada de uma política criminal cujo conteúdo é de difícil delimitação, ainda que se argumente possuir uma base constitucional. Estas análises conduziram a pesquisa ao estudo dos impactos da corrupção sistêmica produzida pela alopoiese por sobre o sistema jurídico (penal), o qual perde sua autonomia e passa a operar mediante estruturas e programas característicos de sistemas sociais expansivos que compõem o ambiente (política, economia, dentre outros).

5. Para delimitar o objeto de estudo e da verificação empírica a ser realizada, a pesquisa se dedicou em seu segundo capítulo à proporcionalidade concebida enquanto exigências de correlação gradativa entre seriedade do comportamento criminoso e gravidade da sanção jurídico-penal. O estudo dos correspondentes filosófico da proporcionalidade das penas possibilitou expor seus correspondentes com o preenchimento dogmático atribuído em um segundo momento pela doutrina penalista, de modo a articular a ideia de proporcionalidade penal ao significado, fundamento e finalidades da punição estatal. Esta 
exigência de relação equilibrada entre conduta e pena implica a noção de "proporcionalidade abstrata", a qual incide no âmbito legislativo e determina que a correlação gradativa se dê entre pena e injusto; e "proporcionalidade concreta", aplicável no momento judicial, tendo como critério para definição da pena proporcional a gravidade do injusto conjugada com as causas de diminuição que podem resultar de um juízo de culpabilidade.

6. A proporcionalidade das penas, essencialmente retrospectiva, não se confunde com a proporcionalidade em sentido amplo, esta de caráter prospectivo e cujo principal campo de incidência são as situações jurídicas caracterizadas por uma relação de meio e fim. A difusão de teorias penalistas que concebem o direito penal como teleologicamente orientado incrementa as possibilidades de a proporcionalidade em sentido amplo operar como critério interpretativo voltado à verificação da procedência constitucional de restrições a direitos fundamentais, mediante a submissão da medida estatal a um exame de aferição de compatibilidade constitucional composto por três regras a serem sucessivamente perpassadas: idoneidade, necessidade e proporcionalidade em sentido estrito, tendo o conteúdo dogmático de cada uma delas sido explorado criticamente no terceiro capítulo.

7. As conclusões da análise das máximas de proporcionalidade, por sua vez, foram no sentido de que elas servem como importantes mecanismos interpretativos de restrições de direitos fundamentais decorrentes de conflitos jurídico-penais, tendo uma complexidade dogmática apta a fornecer critérios de mediação das tensões normativas decorrentes de contradições penais entre a ampliação e restrição de direitos ("proibição do excesso" e "proteção da proteção insuficiente"). Contudo, o caráter formal de sua estrutura aplicativa, os problemas internos à teoria principialista de Alexy, bem como a frequente aplicação assistemática da proporcionalidade conduzem esta ao risco de ser utilizada como mero referencial retórico de justificação formalista de criminalizações.

8. O estudo dos riscos da fundamentação constitucional do direito penal e da política criminal sob o prisma da alopoiese, conjugado com a análise da estrutura dogmática das regras de proporcionalidade, incrementaram a capacidade crítico-analítica da pesquisa na observação empírica do comportamento decisório dos Ministros do STF nos acórdãos em que recorreram à proporcionalidade para solucionar casos de direito penal material entre $2011 \mathrm{e}$ 2012. A análise quantitativa revelou uma aplicação principalmente nominalista da proporcionalidade, cujo resultado final transita entre a limitação e a justificação do poder punitivo, embora esta última possibilidade tenha se mostrado a mais numerosa. A descrição 
das linhas argumentativas dos Ministros acerca da proporcionalidade, por sua vez, coaduna-se com os resultados obtidos a partir da verificação quantitativa, também indicando uma utilização predominantemente retórica da proporcionalidade, na condição de reforço argumentativo de posicionamentos que apontam ainda à veiculação de uma política criminal judiciária.

A utilização da proporcionalidade na argumentação dos Ministros do Supremo Tribunal Federal nos acórdãos que compuseram a amostra, destarte, confirmou a hipótese inicial de investigação, segundo a qual a proporcionalidade é utilizada principalmente como instrumento retórico de reposição argumentativa, tanto para conter quanto para justificar o poder punitivo. No entanto, a pesquisa acabou por revelar também problemas na própria vinculação entre constituição e direito penal, relação da qual os intérprete-aplicadores extraem juízos político-criminais ora de abrandamento, ora de acentuação da repressividade, em todo caso recorrendo justamente à ordem constitucional e à noção de proporcionalidade - ainda que de maneira vaga e desprovida de qualquer explicação acerca de seu conteúdo dogmático. A proporcionalidade poderia operar como mecanismo de absorção do dissenso interpretativo nos conflitos jurídico-penais, bem como de mediação das tensões normativas entre ampliação e restrição de direitos; ou, ainda, como elemento de articulação entre propósitos de autorreferência e heterorreferência, servindo como barreira às tentativas do entorno de promover corrupção sistêmica em prejuízo da autonomia comunicativa do direito penal. Sua utilização retórica, no entanto, acaba incrementando os riscos de as decisões jurídico-penais fundamentadas com base na proporcionalidade se prestarem à acomodação de interesses particularistas, bem como de o sistema ter sua clausura operativa prejudicada pelas tendências expansivas do ambiente. Daí a necessidade de serem buscados novos modelos deliberativos ao STF, e o desenvolvimento de métodos argumentativos que possibilitem um maior controle intersubjetivo das decisões. 


\section{REFERÊNCIAS}

AARNIO, Aulis. La tesis de la única respuesta correcta y el principio regulativo del razonamiento jurídico. op. cit., p. 56, 59-60. Doxa, Cuadernos de Filosfía del Derecho, n. 8, 1990, p. 32. Disponível em: <http://hdl.handle.net/10045/10797>. Acesso em: 02 Mai. 2014.

ABANTO VÁSQUEZ, Manuel. El funcionalismo radical o sistémico en el derecho penal económico. In: AVALOS RODRÍGUEZ, Constante Carlos; QUISPE VILLANUEVA, Alejandro Emilio. Libro homenaje a los professores Eugenio Raúl Zaffaroni y Klaus Tiedemann. Lima: Ara Editores, 2008.

ADORNO, Sérgio. Insegurança versus direitos humanos: entre a lei e a ordem. Tempo Social, Revista de Sociologia da USP, vol. 11, n. 2, out. 1999.

. O gerenciamento público da violência urbana: a justiça em ação. In: PINHEIRO, Paulo Sérgio (org.). São Paulo sem medo: um diagnóstico da violência urbana. Rio de Janeiro: Garamond, 1998.

ADORNO, Theodor W. et al. La personalidade autoritaria (prefacio, introducción y conclusiones). Trad. Julia A. del Pino Artacho. Empiria - Revista de Metodología de Ciencias Sociales, n. 12, jul.-dez., 2006.

ADORNO, Theodor. A dialética negativa. Trad. Marco Antônio Casanova. Rio de Janeiro: Zahar, 2009.

AGAMBEN, Giorgio. Estado de exceção. Trad. Iraci D. Poleti. 2. ed. São Paulo: Boitempo, 2004.

AGUADO CORREA, Teresa. El principio de proporcionalidad en derecho penal. Madrid: Edersa, 1999.

. El principio de proporcionalidad en el Derecho Penal peruano. In: CARBONELL, Miguel; GRÁNDEZ CASTRO, Pedro P. (coord.). El principio de proporcionalidad en el derecho contemporáneo. Lima: Palestra, 2010.

. Inexigibilidad de otra conducta en derecho penal: manifestaciones del principio de inexigibilidad en las categorías del delito. Granada: Editorial Comares, 2004.

. Manifestaciones del principio de inexigibilidad de otra conducta en las categorías del delito. Revista Peruana de Ciencias Penales, Lima: IDEMSA, n. 17, 2005.

ALÁEZ CORRAL, Benito. Reflexiones jurídico-constitucionales sobre la prohibición del velo islámico integral en Europa. Direitos Fundamentais \& Justiça, ano 6, n. 18, jan.-mar. 2012.

ALEXY, Robert. Abwägung, Verfassungsgerichtsbarkeit und Repräsentation. In: BECKER, Michael; ZIMMERLING, Ruth (org.). Politik und Recht. Wiesbaden: VS Verlag für Sozialwissenschaften; GW Fachverlage GmbH, 2006.

. Derecho injusto, retroactividad y el principio de legalidad penal. La doctrina del Tribunal Constitucional Federal alemán sobre los homicidios cometidos por los centinelas del Muro de Berlín. Trad. A. Daniel Oliver-Lalana. Doxa, Cuadernos de Filosofía del Derecho, vol. 23, 2000 . El concepto y la validez del derecho. Trad. Jorge M. Seña. 2. ed. Barcelona: Editorial Gedisa, 2004.

ALEXY, Robert. La fórmula del peso. Trad. Carlos Bernal Pulido. In: CARBONELL, Miguel; GRÁNDEZ CASTRO, Pedro P. (coord.). El principio de proporcionalidad en el derecho contemporáneo. Lima: Palestra, 2010.

. La institucionalización de la justicia. Trad. José Antonio Seoane, Eduardo Roberto Sodero e Pablo Rodríguez. Granada: Editorial Comares, 2005. 
. Los derechos fundamentales y el principio de proporcionalidad. Trad. Jorge Alexander Portocarrero Quispe. Revista Española de Derecho Constitucional, n. 91, 2011.

. Posfácio (2002). In: ALEXY, Robert. Teoria dos direitos fundamentais. Trad. Virgílio Afonso da Silva. 2. ed. São Paulo: Malheiros, 2012.

. Teoria dos direitos fundamentais. Trad. Virgílio Afonso da Silva. 2. ed. São Paulo: Malheiros Editores, 2012.

AMARAL, Cláudio do Prado. Bases teóricas da ciência penal contemporânea: dogmática, missão do direito penal e política criminal na sociedade de risco. São Paulo: IBCCRIM, 2007.

. Princípios penais: da legalidade à culpabilidade. São Paulo: IBCCRIM, 2003.

AMELUNG, Knut. El concepto "bien jurídico" en la teoría de la protección penal de bienes jurídicos. Trad. Íñigo Ortiz de Urbina Gimeno. In: HEFENDEHL, Roland [ed]. La teoría del bien jurídico: ¿Fundamento de legitimación del derecho penal o juego de abalorios dogmático? Madrid: Marcial Pons, 2007.

. Rechtsgüterschutz und Schutz der Gesellschaft. Frankfurt am Main: Athenäum Verlag GmbH, 1972.

ANDRÉS IBÁÑEZ, Perfecto. Acerca de la motivación de los hechos en la sentencia penal. Doxa, n. 12, 1992, p. 264-265. Disponível em: 〈http://hdl.handle.net/10045/10731〉. Acesso em: 02 Mai. 2014.

ARIAS HOLGUIN, Diana Patricia. Proporcionalidad, pena y principio de legalidad. Revista de Derecho, Barranquilla: Ediciones Uninorte, n. 38, jul.-dez. 2012.

ARROYO ZAPATERO, Luis. Derecho penal económico y constitución. Revista Penal, ano 1, n. 1, 1997.

ASP, Petter. Two notions of proportionality. Disponível em: <portal.uclm.es/portal/page/portal/IDP/Crimpol/P\%20Raimo\%20FS.pdf>. Acesso em: 28 Nov. 2014.

. Two notions of proportionality. In: NUOTIO, Kimmo (ed.). Festschrift in Honour of Raimo Lahti. Helsinki: Forum Iuris, 2007.

ATIENZA, Manuel. Contribución para una teoría de la legislación. Doxa: Cuadernos de Filosofía del Derecho, n. 06, 1989.

. Sobre la argumentación en materia de hechos. Comentario crítico a las tesis de Perfecto Andrés Ibáñez. In: ATIENZA, Manuel. Cuestiones judiciales. México, D.F.: Distribuciones Fontamara, 2001.

ÁVILA, Humberto. "Neoconstitucionalismo": entre a "ciência do direito" e o "direito da ciência". Revista Eletrônica de Direito do Estado, Salvador, n. 17, jan.-mar. 2009, p. 7-8 e 10. Disponível em: <http://www.direitodoestado.com/revista/rede-17-janeiro-2009-humberto\%20avila.pdf >. Acesso em: 25 Fev. 2015.

. A distinção entre princípios e regras e a redefinição do dever de proporcionalidade. Revista Diálogo Jurídico, Salvador, CAJ - Centro de Atualização Jurídica, v. I, nº. 4, julho, 2001. Disponível em: <http://www.direitopublico.com.br>. Acesso em: 09 Out. 2014.

ÁVILA, Humberto. Teoria dos princípios: da definição à aplicação dos princípios jurídicos. 9. ed. São Paulo: Malheiros, 2009.

. Teoria dos princípios: da definição à aplicação dos princípios jurídicos. 4. ed. São Paulo: Malheiros, 2005.

AZEVEDO, Antonio Junqueira de. Caracterização jurídica da dignidade da pessoa humana. Revista USP, n. 53, mar.-mai., 2002. 
BACIGALUPO, Enrique. Derecho penal y el estado de derecho. Santiago: Editorial Jurídica de Chile, 2005.

. Dominio del hecho, autoría mediata y derecho penal internacional. Anuario de Derecho Penal, Buenos Aires: Ad Hoc, Departamento de Derecho Penal y Criminología, UBA, 2010-2011.

. Principios constitucionales de derecho penal. Buenos Aires: Editorial Hammurabi, 1999.

. Tribunal Supremo y Tribunal Constitucional en la protección de los derechos fundamentales. In: BACIGALUPO, Enrique. Justicia penal y derechos fundamentales. Madrid: Marcial Pons, 2002.

BADARÓ, Gustavo Henrique Righi Ivahy. Processo penal. Rio de Janeiro: Elsevier, 2012.

BARATTA, Alessandro. Funciones instrumentales y simbólicas del derecho penal: una discusión en la perspectiva de la criminología crítica. Trad. Mauricio Martínez Sánchez. In: BUSTOS RAMÍREZ, Juan (dir.). Pena y estado: función simbólica de la pena. Santiago: Editorial Jurídica ConoSur, 1995.

BARROSO, Luís Roberto. Curso de direito constitucional contemporâneo: os conceitos fundamentais e a construção do novo modelo. São Paulo: Saraiva, 2009.

- Interpretação e aplicação da constituição: fundamentos de uma dogmática constitucional transformadora. 7. ed. rev. São Paulo: Saraiva, 2009.

BAUMAN, Zygmunt. Medo líquido. Trad. Carlos Alberto Medeiros. Rio de Janeiro: Zahar, 2008.

BECCARIA, Cesare. Dos delitos e das penas. Trad. Alexis Augusto Couto de Brito. São Paulo: Quartier Latin, 2005, p. 47; e MONTESQUIEU, Charles de Secondat, Baron de. O espírito das leis. Trad. Cristina Murachco. São Paulo: Martins Fontes, 1996.

BECHARA, Ana Elisa Liberatore Silva. Critérios político-criminais da intervenção penal no âmbito econômico: uma lógica equivocada. In: FRANCO, Alberto Silva; LIRA, Rafael [coord.]. Direito penal econômico: questões atuais. São Paulo: Editora Revista dos Tribunais, 2011.

. Da teoria do bem jurídico como critério de legitimidade do direito penal. Tese de Livre-Docência apresentada à Faculdade de Direito da Universidade de São Paulo. São Paulo, 2010.

BECK, Ulrich. La sociedad del riesgo: hacia una nueva modernidad. Trad. Jorge Navarro, Daniel Jiménez e María Rosa Borrás. Barcelona: Editorial Paidós, 1998.

BENTHAM, Jeremy. An introduction to the principles of morals and legislation. Kitchener: Batoche Books, 2000.

BERGER, Peter L.; LUCKMANN, Thomas. La construcción social de la realidad. Trad. Silvia Zuleta. Buenos Aires: Amorrortu, 1991.

BERNAL PULIDO, Carlos. Consideraciones acerca de la fórmula de la ponderación de Robert Alexy. In: MONTEALEGRE, Eduardo (coord.). La ponderación en el derecho. Bogotá: Universidad Externado de Colombia, 2008.

. Estructura y límites de la ponderación. Doxa, n. 26, 2003.

. La racionalidad de la ponderación. In: CARBONELL, Miguel; GRÁNDEZ CASTRO, Pedro P. (org.). El principio de proporcionalidad en el derecho contemporáneo. Lima: Palestra Editores, 2010.

. Proporcionalidad, derechos fundamentales y ley penal. In: LASCURAÍN SÁNCHEZ, Juan Antonio; RUSCONI, Maximiliano (dir.). El principio de proporcionalidad penal. Buenos Aires: Editorial Ad Hoc, 2014. 
. Tribunal Constitucional, legislador y principio de proporcionalidad: uma respuesta a Gloria Lopera. Revista Española de Derecho Constitucional, Madrid: Centro de Estudios Políticos y Constitucionales, ano 25, n. 74, mai.-ago., 2005.

BITENCOURT, Cezar Roberto. Falência da pena de prisão: causas e alternativas. 4. ed. São Paulo: Saraiva, 2011.

BITTAR, Walter Barbosa. Delação premiada no Brasil e na Itália: uma análise comparativa. Revista Brasileira de Ciências Criminais, São Paulo: Editora Revista dos Tribunais, Ano 19, n. 88, jan.-fev. 2011.

BOBBIO, Norberto. O positivismo jurídico. Trad. Márcio Pugliesi, Edson Bini, Carlos E. Rodrigues São Paulo: Ícone, 1995.

. Prologo. In: FERRAJOLI, Luigi. Derecho y razón: teoría del garantismo penal. Trad. Perfecto Andrés Ibáñéz, Alfonso Ruiz Miguel, Juan Carlos Bayón Mahino et al. Madrid: Editorial Trotta, 1995.

- Teoria do ordenamento jurídico. Trad. Maria Celeste C. J. Santos. 6. ed. Brasília: Editora Universidade de Brasília, 1995.

BOBBIO, Norberto; MATEUCCI, Nicola; PASQUINO, Gianfranco. Dicionário de política, vol. 1. Trad. Carmen C. Varriale et al. Brasília: Editora UNB, 1998.

BÖCKENFÖRDE, Ernst-Wolfgang. Escritos sobre derechos fundamentales. Trad. Juan Luis Requejo Pagés e Ignacio Villaverde Menéndez. Baden-Baden: Nomos Verlagsgesellschaft, 1993.

BOLEA BARDON, Carolina. En los límites del derecho penal frente a la violencia doméstica y de género. Revista Electrónica de Ciencia Penal y Criminología, n. 09-02, 2007, p. 24. Disponível em: < http://criminet.ugr.es/recpc/09/recpc09-02.pdf>. Acesso em: 21 Mar. 2014.

BONAVIDES, Paulo. Curso de direito constitucional. 15. ed. São Paulo: Malheiros, 2005.

BOROWSKI, Martin. La estructura de los derechos fundamentales. Trad. Carlos Bernal Pulido. Bogotá: Universidad Externado de Colombia, 2003.

BOTTINI, Pierpaolo Cruz. O princípio da proporcionalidade na produção legislativa brasileira e seu controle judicial. Revista Brasileira de Ciências Criminais, São Paulo: Editora Revista dos Tribunais, ano 18, n. 85, jul.-ago. 2010.

. Princípio da precaução, direito penal e sociedade de risco. Revista Brasileira de Ciências Criminais, São Paulo: Editora Revista dos Tribunais, n. 61, v. 14, 2006.

BOTTINI, Pierpaolo et al. A confusa exegese do princípio da insignificância e sua aplicação pelo STF: análise estatística de julgados. Revista Brasileira de Ciências Criminais, São Paulo: Editora Revista dos Tribunais, ano 20, n. 98, set.-out., 2012.

BRAGA, Ana Gabriela Mendes. A identidade do preso e as leis do cárcere. Dissertação de Mestrado apresentada à Faculdade de Direito da Universidade de São Paulo. São Paulo, 2008.

BRICOLA, Franco. Teoria generale del reato. Novissimo Digesto Italiano, XIX. Turim: Unione Tipografico Editrice Torinese, 1973.

BROOKS, Thom. Hegel's political philosophy: a systematic reading of the Philosophy of Right. Edimburgo: Edinburgh University Press, 2009.

BUCHARD, Christoph. O princípio de proporcionalidade no "direito penal constitucional" ou o fim da teoria do bem jurídico tutelado na Alemanha. Trad. Fabíola Girão de Monteconrado. In: AMBOS, Kai; BÖHM, María Laura (coord.). Desenvolvimentos atuais das ciências criminais na Alemanha. Brasília-DF: Gazeta Jurídica, 2013. 
CALLIESS, Christian. Dimensions of fundamental rights. In: Pünder, Hermann; WALDHOFF, Christian. Debates in german public law. Oxford, Portland: Hart Publishing, 2014.

CAMARGO, Antonio Luís Chaves. Imputação objetiva e direito penal brasileiro. São Paulo: Cultural Paulista, 2002.

CAMPILONGO, Celso Fernandes. Interpretação do direito e movimentos sociais: hermenêutica do sistema jurídico e da sociedade. Rio de Janeiro: Elsevier, 2012 (recurso digital).

Política, sistema jurídico e decisão judicial. 2. ed. São Paulo: Saraiva, 2011.

CANARIS, Claus-Wilhelm. Direitos fundamentais e direito privado. Trad. Ingo Wolfgang Sarlet e Paula Mota Pinto. Coimbra: Almedina, 2009; BÖCKENFÖRDE, Ernst-Wolfgang. Stato, costituzione, democrazia: studi di teoria dela costituzione e di diritto costituzionale. Trad. Michele Nicoletti e Omar Brino. Milão: Giuffre, 2006.

. Pensamento sistemático e conceito de sistema na ciência do direito. Trad. A. Menezes Cordeiro. Lisboa: Fundação Calouste Gulbenkian, 1989.

CANO, Ignacio. Direitos humanos, criminalidade e segurança pública. In: BRASIL, Presidência da República. Direitos humanos: percepções da opinião pública: análises de pesquisa nacional. Organização por Gustavo Venturini. Brasília: Secretaria de Direitos Humanos, 2010.

CANOTILHO, José Joaquim Gomes. Direito constitucional e teoria da constituição. 7. ed. Coimbra: Edições Almedina, 2003.

CARBONELl MATEU, Juan Carlos. Derecho penal: concepto y principios constitucionales. 3. ed. Valencia: Tirant lo Blanch, 1999.

CARO JOHN, José Antonio. A ponderação entre o direito à honra e o direito à liberdade de expressão. Trad. Eduardo Saad-Diniz. In: POLAINO-ORTS, Miguel; SAAD-DINIZ, Eduardo (org.). Teoria da pena, bem jurídico e imputação. São Paulo: LiberArs, 2012.

CARO JOHN, José Antonio; POLAINO-ORTS, Miguel. El neokantismo de la primera escuela de Frankfurt. In: ZACZYK, Rainer. Libertad, derecho y fundamentación de la pena. Eduardo Montealegre Lynett, Nathalia Bautista Pizarro, José Antonio Caro John e Miguel Polaino-Orts (comp.). Bogotá: Universidad Externado de Colombia, 2010.

CARPINTERO BENITEZ, Francisco. Del derecho natural medieval al derecho natural moderno: Fernando Vazquez de Menchaca. Salamanca: Universidad de Salamanca, 1977.

CARRARA, Francesco. Programa de derecho criminal: parte general, vol. II. Trad. José J. Ortega Torres e Jorge Guerrero. 4. ed. Bogotá: Editorial Temis, 1991.

CARVALHO, Salo de. Sobre a criminalização da homofobia: perspectivas desde a criminologia queer. Revista Brasileira de Ciências Criminais, São Paulo: Editora Revista dos Tribunais, n. 99, 2012.

CASTIÑEIRA, Maria Teresa; RAGUÉS, Ramon. Three strikes. El principio de proporcionalidad en la jurisprudencia del Tribunal Supremo de los Estados Unidos. In: CARBONELL, Miguel; GRÁNDEZ CASTRO, Pedro P. (coord.). El principio de proporcionalidad en el derecho contemporáneo. Lima: Palestra, 2010.

CEREZO MIR, José. Curso de derecho penal español, parte general, tomo II: teoría jurídica del delito. Madrid: Editorial Tecnos, 2005.

. La doble posición del dolo en la ciencia del derecho penal española. Anuario de Derecho Penal y Ciencias Penales, Madrid, Tomo XXXV, Fascículo I, jan-abr. 1998.

CLAPHAM, Andrew. Human rights in the private sphere. Oxford: Clarendon Press, 1993. 
CLÉRICO, Laura. El examen de proporcionalidad en el derecho constitucional. Buenos Aires: Universidad de Buenos Aires, 2009.

. El examen de proporcionalidad: entre el exceso por acción y la insuficiencia por omisión o defecto. In: CARBONELL, Miguel; GRÁNDEZ CASTRO, Pedro P. (coord.). El principio de proporcionalidad en el derecho contemporáneo. Lima: Palestra, 2010.

. Proporcionalidad, prohibición de insuficiencia y la tesis de la alternatividad. In: CLÉRICO, Laura; SIECKMANN, Jan-R.; OLIVER-LALANA, Daniel (coord.). Derechos fundamentales, principios y argumentación: estudios sobre la teoría jurídica de Robert Alexy. Granada: Editorial Comares, 2011.

CORSI, Giancarlo; ESPOSITO, Elena; BARALDI, Claudio. GLU: glosario sobre la teoría social de Niklas Luhmann. Trad. Miguel Romero Pérez e Carlos Villalobos. México, D.F.: Universidad Iberoamericana, 1996.

COSTA, Antônio Carlos Luz. Irritation und Allopoiesis im Rechtssystem: eine systemtheorestische Analyse der polizeilichen Beobachtung in der Stadt Teixeira de Freitas, Brasilien. Tese de doutoramento apresentada perante a Universidade de Hamburgo. Hamburgo, 2012. Disponível em: < http://ediss.sub.uni-hamburg.de/volltexte/2012/5498/pdf/Dissertation.pdf >. Acesso em: 23 Mar. 2014.

COSTA, Helena Regina Lobo da. A dignidade humana: teorias de prevenção geral positiva. São Paulo: Editora Revista dos Tribunais, 2008

. Considerações sobre o estado atual da teoria do bem jurídico à luz do harm principle. In: GRECO, Luís; MARTINS, Antonio (org.). Direito penal como crítica da pena: estudos em homenagem a Juarez Tavares por seu $70^{\circ}$ aniversário em 2 de setembro de 2002. São Paulo: Marcial Pons, 2012.

. Os crimes ambientais e sua relação com o direito administrativo. In: VILARDI, Celso Sanchez; PERREIRA, Flávia Rahal Bresser; DIAS NETO, Theodomiro. Direito penal econômico: análise contemporânea. São Paulo: Saraiva, 2009.

COSTA, José de Faria. Uma ponte entre o direito penal e a filosofia penal: lugar de encontro sobre o sentido da pena. In: DIAS, Jorge de Figueiredo; CANOTILHO, José Joaquim Gomes; COSTA, José de Faria. Ars iudicandi: estudos em homenagem ao Prof. Doutor António Castanheira Neves, vol. 1: filosofia, teoria e metodologia. Coimbra: Coimbra Editora, 2008.

CUERDA ARNAU, María Luisa. Proporcionalidad penal. Libertad de expresión y efecto de desaliento. Su proyección sobre los nuevos tipos de apología. In: LASCURAÍN SÁNCHEZ, Juan Antonio; RUSCONI, Maximiliano (dir.). El principio de proporcionalidad penal. Buenos Aires: Editorial Ad Hoc, 2014.

CUNHA, Maria da Conceição Ferreira da. Constituição e crime: uma perspectiva da criminalização e da descriminalização. Porto: Universidade Católica Portuguesa, 1995.

D'AVILA, Fabio Roberto. O direito penal na "luta contra o terrorismo". In: ANDRADE, Manual da Costa; COSTA, José de Faria; RODRIGUES, Anabela Miranda et al. Direito penal: fundamentos dogmáticos e político-criminais. Homenagem ao Prof. Peter Hünerfeld. Coimbra: Coimbra Editora, 2013.

- Ofensividade em direito penal: escritos sobre a teoria do crime como ofensa a bens jurídicos. Porto Alegre: Livraria do Advogado Editora, 2009.

DEMETRIO CRESPO, Eduardo. Crítica al funcionalismo normativista. Revista de Derecho Penal y Criminología, 3. Época, n. 3, 2010. 
. El derecho penal del enemigo darf nicht sein! Sobre la ilegitimidad del llamado "Derecho penal del enemigo" y la idea de seguridad. In: MELÍA, Cancio; DÍEZ. Gómez-Jara. Derecho penal del enemigo: el discurso penal de la exclusión, vol. 1. Buenos Aires: Euros Editores, 2006.

DIAS, Camila Caldeira Nunes. Da pulverização ao monopólio da violência: expansão e consolidação do Primeiro Comando da Capital (PCC) no sistema carcerário paulista. Tese de doutoramento apresentada à Faculdade de Filosofia, Letras e Ciências Humanas da Universidade de São Paulo. São Paulo, 2011.

DIAS, Jorge de Figueiredo. Direito penal. Parte geral, t. I. Coimbra: Coimbra Editora, 2004.

DIEZ RIPOLLÉS, José Luis. El derecho penal simbólico y los efectos de la pena. Boletín Mexicano de Derecho Comparado, vol. XXXV, n. 103, jan.-abr. 2002.

. La racionalidad de las leyes penales. Madrid: Editorial Trotta, 2003.

DOMÉNECH PACUAL, Gabriel. Los derechos fundamentales a la protección penal. Revista Española de Derecho Constitucional, n. 78, set.-dez. 2006.

DONINI, Massimo. Principios constitucionales y sistema penal. Modelo y programa. In: LUZÓN PEÑA, Diego-Manuel. Derecho penal del estado social y democrático de derecho: libro homenaje a Santiago Mir Puig. Madrid: La Ley, 2010.

. Un derecho penal fundado en la carta constitucional: razones y límites. La experiencia italiana. Revista Penal, n. 8, 2001.

DONNA, Edgardo Alberto. ¿Es posible el derecho penal liberal? Revista de Derecho Penal, n. 1, 2003.

DWORKIN, Ronald. Levando os direitos a sério. Trad. Nelson Boeira. São Paulo: Martins Fontes, 2007.

. O direito da liberdade: a leitura moral da Constituição norte-americana. Trad. Marcelo Brandão Cipolla. São Paulo: Martins Fontes, 2006.

. O império do direito. Trad. Jefferson Luiz Camargo. 2. ed. São Paulo: Martins Fontes, 2007.

. Uma questão de princípio. Trad. Luís Carlos Borges. 2. ed. São Paulo: Martins Fontes, 2005

DYDE, S. W. Hegel's conception of crime and punishment. The Philosophical Review, vol. 7, n. 1, jan. 1898.

ENGELS, Friedrich; KAUTSKY, Karl. O socialismo jurídico. Trad. Lívia Cotrim e Márcio Bilharinho Naves. 2. ed. rev. São Paulo: Boitempo, 2012.

ENGISCH, Karl. Introdução ao pensamento jurídico. Trad. J. Baptista Machado. 6. ed. Lisboa: Fundação Calouste Gulbenkian, 1988.

EZCURDIA LAVIGNE, Jose A. Curso de derecho natural. Perspectivas iusnaturalistas de los derechos humanos. (Parte General). Madrid: Reus, 1987.

FARALDO CABANA, Patricia. Razones para la introducción de la perspectiva de género en Derecho penal a través de la Ley Orgánica 1/2004, de 28 de diciembre, sobre medidas de protección integral contra la violencia de género. Revista Penal, n. 17, 2006.

FEIJÓO SÁNCHEZ, Bernardo. Las teorías clásicas de la pena. Revista Peruana de Ciencias Penales, Lima: Idemsa, ano VII-VIII, n. 11-12.

. Sobre a "administrativização" do direito penal na "sociedade do risco". Notas sobre a política criminal no início do século XXI. Revista Liberdades, São Paulo: Instituto Brasileiro de Ciências Criminais, n. 7, mai.-ago.

FEINBERG, Joel. Harm to others: the moral limits of the criminal law. New York: Oxford University Press, 1984. 
FELDENS, Luciano. Direitos fundamentais e direito penal: a constituição penal. 2 ed. Porto Alegre: Livraria do Advogado, 2012.

FERNANDES, Fernando Andrade. Sobre uma opção jurídico-política e jurídico-metodológica de compreensão das ciências jurídico-criminais. In: ANDRADE, Manuel da Costa. Liber discipulorum para Jorge de Figueiredo Dias. Coimbra: Coimbra Editora, 2003.

FERNÁNDEZ CRUS, José. El juicio constitucional de proporcionalidade de las leyes penales: ¿La legitimación democrática como medio para mitigar su inherente irracionalidad? Revista de Derecho Universidad Católica del Norte, ano 17, n. 1, 2010.

FERNANDEZ-GALIANO, Antonio. Derecho natural: introducción filosófica al derecho. 5. ed. Madrid: Editorial Ceura, 1986.

FERRAJOLI, Luigi. Derecho y razón: teoría del garantismo penal. Trad. Perfecto Andrés Ibáñéz, Alfonso Ruiz Miguel, Juan Carlos Bayón Mahino et al. Madrid: Editorial Trotta, 1995.

FERRAZ JR., Tercio Sampaio. Teoria da norma jurídica: ensaio de pragmática da comunicação normativa. Rio de Janeiro: Forense, 2006. . Introdução ao estudo do direito. 4. ed. São Paulo: Editora Atlas, 2003. . Introdução ao estudo do direito: técnica, decisão, dominação. 5. ed. São Paulo: Atlas, 2007.

FISS, Owen M. The irony of free speech. Cambridge: Harvard University Press, 1996.

FORST, Rainer. Contexts of justice: political philosophy beyond liberalism and communitarianism. Trad. John M. M. Farrell. Berkeley, Los Angeles: University of California Press, 2002.

FOUCAULT, Michel. Os anormais: curso no Collège de France. Trad. Eduardo Brandão. São Paulo: Editora WMF Martins Fontes, 2010. . Vigiar e punir: nascimento da prisão. Trad. Raquel Ramalhete. 20. ed. Petrópolis: Vozes, 1987.

FRANCÉS LECUMBERRI, Paz. El principio de oportunidad y la justicia restaurativa: mediación, conciliación y reparación en la Ley Orgánica de responsabilidad penal del menor. InDret - Revista para el Análisis del Derecho, Barcelona, n. 4, out. 2012, p. 6. Disponível em: <www.indret.com/pdf/921.pdf>. Acesso em: 20 Fev. 2014.

FRANCO, Alberto Silva. Crimes hediondos: anotações sistemáticas à lei 8.072/90. 4. ed. rev., atual. e ampl. São Paulo: Editora Revista dos Tribunais, 2000.

FRASE, Richard S. Excessive relative to what? Defining constitutional proportionality principles. In: TONRY, Michael (ed.). Why punish? How Much? A reader on punishment. New York: Oxfor University Press, 2011.

GALINDO MONTEAGUDO, Jorge. La teoría sistémica de la sociedad de Niklas Luhann: alcances y límites. In: LUHMANN, Niklas. La sociedad de la sociedad. Trad. Javier Torres Nafarrete. Ciudad de México: Herder, 2006.

GARCIA AMADO, Juan Antonio. La filosofía del derecho de Habermas y Luhmann. Bogotá: Universidad Externado de Colombia, 1997.

GARCÍA FIGUEROA, Alfonso. La teoría del derecho en tiempos de constitucionalismo. In: CARBONELL, Miguel (ed.). Neoconstitucionalismo(s). 2. ed. Madrid: Editorial Trotta, 2005.

GARCÍA RIVAS, Nicolás. Los principios del derecho penal constitucional (II): el principio de proporcionalidad de las consecuencias jurídicas. In: SERRANO-PIEDECASAS FERNÁNDEZ, José Ramón (comp.). Derecho penal: parte general. Madrid: Iustel, 2002 (versão digital). 
GARCÍA-PABLOS DE MOLINA, Antonio. Criminología: una introducción a sus fundamentos teóricos. 6. ed. Valencia: Tirant lo Blanch, 2007.

GARLAND, David. La cultura del control: crimen y orden social en la sociedad contemporánea. Trad. Máximo Sozzo. Barcelona: Editorial Gedisa, 2005.

GIDDENS, Anthony. As consequências da modernidade. Trad. Raul Fiker. São Paulo: Editora Unesp, 1991.

GIMÉNEZ ALCOVER, Pilar. El derecho en la teoría de la sociedad de Niklas Luhmann. Barcelona: J. M. Bosch Editor, 1993.

GOMES, Mariângela Gama de Magalhães. Direito penal e interpretação jurisprudencial: do princípio da legalidade às súmulas vinculantes. São Paulo: Atlas, 2008.

. Notas sobre as súmulas vinculantes em matéria penal. Revista Brasileira de Ciências Criminais, São Paulo: Editora Revista dos Tribunais, ano 18, n. 84, p. 77-110, mai.-jun., 2010.

. O princípio da proporcionalidade no direito penal. São Paulo: Editora Revista dos Tribunais, 2003.

GONZÁLEZ BEILFUSS, Markus. El principio constitucional de proporcionalidad penal en España. In: LASCURAÍN SÁNCHEZ, Juan Antonio; RUSCONI, Maximiliano (dir.). El principio de proporcionalidad penal. Buenos Aires: Editorial Ad Hoc, 2014.

. El principio de proporcionalidad en la jurisprudencia del Tribunal Constitucional. Navarra: Thomson Arazandi, 2003.

GRAU, Eros. Ensaio e discurso sobre a interpretação/aplicação do direito. 4. ed. São Paulo: Malheiros, 2006.

GRECO, Luís. Introdução à dogmática funcionalista do delito: em comemoração aos trinta anos de "Política criminal e sistema jurídico-penal" de Roxin. Revista Brasileira de Ciências Criminais, São Paulo: Editora Revista dos Tribunais, n. 32, out.-dez., 2012

. Tem futuro a teoria do bem jurídico? Reflexões a partir da decisão do Tribunal Constitucional Alemão a respeito do crime de incesto ( $\$ 173$ Strafgesetzbuch). Revista Brasileira de Ciências Criminais, São Paulo: Editora Revista dos Tribunais, ano 18, n. 82, jan.-fev., 2010.

. Verfassungskonformes oder legitimes Strafrecht? Zu den Grenzen einer verfassungsrechtlichen Orientierung der Strafrechtswissenschaft. In: BRUNHÖBER, B.; HÖFFLER, K; KASPAR; J. et al. Strafrecht und Verfassung. Baden-Baden: Nomos, 2013.

GRIMM, Dieter. Multiculturalidad y derechos fundamentales. Trad. Ignacio Gutiérrez Gutiérrez. In: DENNINGER, Erhard; GRIMM, Dieter. Derecho constitucional para la sociedad multicultural. Madrid: Editorial Trotta, 2005.

GUASTINI, Riccardo. A “constitucionalização" do ordenamento jurídico: o caso italiano. Trad. José María Lujambio. In: . In: CARBONELL, Miguel (ed.). Neoconstitucionalismo(s). 2. ed. Madrid: Editorial Trotta, 2005, p. 49.

Das fontes às normas. Trad. Edson Bini. São Paulo: Quartier Latin, 2005.

. Ponderación: un análisis de los conflitos entre principios constitucionales. Trad. Pedro P. Grández Castro. In: CARBONELL, Miguel; GRÁNDEZ CASTRO, Pedro P. (coord..). El principio de proporcionalidad en el derecho penal contemporáneo. Lima: Palestra Editores, 2010.

GUERRA FILHO, Willis Santiago. Sobre o princípio da proporcionalidade. LEITE, George Salomão (org.). Dos princípios constitucionais: considerações em torno das normas principiológicas da constituição. São Paulo: Malheiros, 2003. 
- Teoria constitucional dos princípios jurídicos como teoria fundamental do direito e garantismo penal. Revista Mestrado em Direito, Osasco, ano 6, n. 1, 2006.

GÜNTHER, Klaus. Ciudadano cosmopolita entre libertad y seguridad. Trad. Peter Storandt. In: LEYVA, Gustavo (ed.). La teoría crítica y las tareas actuales de la crítica. Rubí (Barcelona): Anthropos Editorial; México: Universidad Autónoma Metropolitana - Iztapalapa, 2005.

GUSFIELD, Joseph R. Symbolic crusade: status politics and the American temperance movement. Urbana, Londres: University of Illinois Press, 1966.

GUSTIN, Miracy Barbosa de Sousa; DIAS, Maria Tereza Fonseca. (Re)pensando a pesquisa jurídica: teoria e prática. 2. ed. rev., ampl. e atual. Belo Horizonte: Del Rey, 2006.

HÄBERLE, Peter. Pluralismo y constitución: estudios de teoría constitucional de la sociedad aberta. Trad. Emilio Mikunda-Franco. Madrid: Editorial Tecnos, 2002.

. Hermenêutica constitucional: a sociedade aberta dos intérpretes da constituição: contribuição para a interpretação pluralista e "procedimental" da constituição. Trad. Gilmar Ferreira Mendes. Porto Alegre: Sergio Antionio Fabris Editor, 1997.

. La garantía del contenido esencial de los derechos fundamentales en la Ley Fundamental de Bonn. Trad. Joaquín Brage Camazano. Madrid: Dykinson, 2003.

HABERMAS, Jürgen. Direito e democracia: entre facticidade e validade, v. 1. Trad. Flávio Beno Siebeneichler. Rio de Janeiro: Tempo Brasileiro, 1997.

. Direito e democracia: entre facticidade e validade, v. 2. Trad. Flávio Beno Siebeneichler. Rio de Janeiro: Tempo Brasileiro, 1997.

. Problemas de legitimación en el capitalismo tardío. Trad. José Luis Etcheverry. Madrid: Cátedra, 1999.

HANDLER, Joel F. Social movements and the legal system: a theory of law reform and social change. New York, San Francisco, London: Academic Press, 1978.

HART, L. A. O conceito de direito. Trad. A. Ribeiro Mendes. 3. ed. Lisboa: Fundação Calouste Gulbenkian, 1994.

HASSEMER, Winfried. ¿Puede Haber delitos que no afecten a un bien jurídico penal? Trad. Beatriz Spínola Tártalo. In: HEFENDEHL, Roland (ed.). La teoría del bien jurídico: ¿Fundamento de legitimación del derecho penal o juego de abalorios dogmático? Madrid: Marcial Pons, 2007.

. Derecho penal simbólico y protección de bienes jurídicos. Trad. Elena Larrauri. In: BUSTOS RAMÍREZ, Juan (dir.). Pena y estado: función simbólica de la pena. Santiago: Editorial Jurídica ConoSur, 1995.

. El destino de los derechos del ciudadano en un derecho penal "eficaz". Trad. Francisco Muñoz Conde. Doctrina penal: teoría y práctica en las ciencias penales, n. 49/52, v. 13, 1990.

. El principio de proporcionalidad como límite de las intervenciones jurídico-penales. In: In: LASCURAÍN SÁNCHEZ, Juan Antonio; RUSCONI, Maximiliano (dir.). El principio de proporcionalidad penal. Buenos Aires: Editorial Ad Hoc, 2014.

. Fundamentos del derecho penal. Trad. Francisco Muñoz Conde e Luis Arroyo Zapatero. Barcelona: Bosch, 1984.

. La "renuncia a la pena" como instrumento de política criminal. Trad. Joan Josep Queralt. In: MIR, Santiago (ed.). La reforma del derecho penal, tomo II. Barcelona: Bellaterra, 1981. 
. La persecución penal: legalidad y oportunidad. Trad. M. A. Cobos Gómez de Linares. Revista de Derecho Penal, n. 2, 2001.

HECK,Philipp. Interpretação da lei e jurisprudência dos interesses. Trad. José Osório. São Paulo: Livraria Acadêmica Saraiva \& Cia., 1947.

HEGEL, Georg Wilhelm Friedrich. Princípios da filosofia do direito. Trad. Orlando Vitorino. São Paulo: Martins Fontes, 1997.

HEGENBARTH, Rainer. Symbolische und instrumentelle Funktionen moderner Gesetze. Zeitschrift für Rechtspolitik, ano 14, caderno 9, set. 1981.

HERRERA MORENO, Myriam. La hora de la víctima: compendio de victimología. Madrid: EDERSA, 1996.

HESSE, Konrad. Significado dos direitos fundamentais. Trad. Carlos dos Santos Almeida. In: HESSE, Konrad. Temas fundamentais do direito constitucional. Org. e trad. Carlos dos Santos Almeida, Gilmar Ferreira Mendes, Inocêncio Mártires Coelho. São Paulo: Saraiva, 2009.

HIRSCH, Andrew von; ASHWORTH, Andrew. Proportionate sentencing: exploring the principles. Oxford: Oxford University Press, 2010.

HIRSCH, Hans Joachim. Acerca de la crítica al finalismo. In: HIRSCH, Hans Joachim. Derecho penal: obras completas, tomo V. Buenos Aires: Rubinzal-Culzoni, 2007.

HÖFFE, Otfried. A democracia no mundo de hoje. Trad. Lívio Cruz Romão. São Paulo: Martins Fontes, 2005.

HOFSTADTER, Douglas. Gössel, Escher, Bach: an eternal golden braid. A metaphorical fuge on minds and machines in the spirit of Lewis Carroll. Sussex: Hassocks, 1979.

I I am a strange loop. New York: Basic Books, 2007.

HOLLERBACH, Alexander. Ideologie und verfassung. In: MAIHOFER, Werner (org.). Ideologie und Recht. Frankfurt a. M.: Klostermann, 1969.

HONNETH, Axel. El derecho de la libertad: esbozo de una eticidad democrática. Trad. Graciela Calderón. Madrid: Clave Intelectual; Buenos Aires: Katz Editores, 2014.

. Luta por reconhecimento: a gramática moral dos conflitos sociais. Trad. Luiz Repa. São Paulo: Editora 34, 2003.

HÖRNLE, Tatjana. La concepción anticuada de la culpabilidad en la jurisprudencia y doctrina tradicionales de la medición de la pena. Trad. María Martín Lorenzo. In: HÖRNLE, Tatjana. Determinación de la pena y culpabilidad: notas sobre la teoría de la determinación de la pena en Alemania. Buenos Aires: Fabián J. Di Plácido, 2003.

HUSAK, Douglas. Retributivism, proportionality, and the challenge of the drug court movement. In: TONRY, Michael (ed.). Retributivism has a past: has it a future? Nova York: Oxford University Press, 2011.

ISENSEE, Josef. Das Grundrecht auf Sicherheit: zu den Schutzpflichten des freiheitlichen Verfassungsstaates. Berlim, Nova York: Walter de Gruyter, 1983.

. Freiheit oder Sicherheit - Ist Deutschland auf dem Weg in den Überwachungsstaat? Horch und Guck, Aktuell un Kontrovers, Heft 59, 2007, p. 60 e ss. Disponível em: <http://www.hugarchiv.de/059/05916.pdf>. Acesso em: 23 Mar. 2014.

IZUZQUIZA, Ignacio. Introducción: la urgencia de una nova lógica. In: LUHMANN, Niklas. Sociedad y sistema: la ambición de la teoría. Trad. Santiago López Petit e Dorothee Schmitz. Barcelona: Paidós, 1997. 
JAKOBS, Günther. Danosidade social? Anotações sobre um problema teórico fundamental do direito penal. Trad. Eduardo Saad-Diniz. In: POLAINO-ORTS, Miguel; SAAD-DINIZ, Eduardo. Teoria da pena, bem jurídico e imputação. São Paulo: LiberArs, 2012.

. Derecho penal, parte general: fundamentos y teoría de la imputación. Trad Joaquin Cuello Contreras e Jose Luis Serrano Gonzales de Murillo. 2. ed. Madrid: Marcial Pons, 1997.

Dolus malus. Trad. Yamila Fakhouri Gómez. InDret, n. 4, 2009. Disponível em: < http://www.indret.com/pdf/674.pdf>. Acesso em: 02 Mai. 2014.

. El desistimiento como modificación del hecho. Trad. Enrique Peñaranda Ramos. In: JAKOBS, Günther. Estudios de derecho penal. Madrid: Editorial Civitas, 1997.

. La imputación jurídico-penal y las confirmaciones de vigencia de la norma. Trad. Javier SánchezVera Gómez-Trellez e Carlos Gómez-Jara Díez. In: GÓMEZ-JARA DÍEZ, Carlos (ed.). Teoría de sistemas y derecho penal: fundamentos y posibilidades de aplicación. Granada: Comares, 2005.

. La imputación objetiva en el derecho penal. Trad. Manuel Cancio Melía. Buenos Aires: Editorial Ad Hoc, 1996.

. Norm, Person, Gesellschaft: Vorüberlegungen zu einer Rechtsphilosophie. Berlim: Duncker \& Humblot, 1997.

. Sobre la normativización de la dogmática jurídico-penal. Trad. Manuel Cancio Melía e Bernardo Fejióo Sánchez. Madrid: Thomson Civitas, 2003.

Sociedad, norma y persona en una teoría de un Derecho penal funcional. Trad. de Manuel Cancio Meliá y Bernardo Feiióo Sánchez. Madrid: Civitas, 2000.

JAKOBS, Günther; CANCIO MELÍA, Manuel. Derecho penal del enemigo. 2. ed. Madrid: ThomsonCivitas: Cizur Menor (Navarra), 2006.

JAPP, Klaus P. The form of protest in the new social movements. In: BAECKER, Dirk (ed.). Problems of form. Trad. Michael Irmscher e Leah Edwards. Standford: Standford University Press, 1999.

JELLINEK, Georg. Diritti pubblici subbiettivi. Trad. Gaetano Vitagliano. Milão: Società Editrice Libraria, 1912.

JEREZ, Miguel. Los grupos de presión. In: DEL ÁGUILA, Rafael (coord.). Manual de ciencia política. 5. ed. Madrid: Editorial Trotta, 2008.

JESCHECK, Hans-Heinrich; WEIGEND, Thomas. Tratado de derecho penal, Parte General. Trad. Miguel Olmedo Cardenete. Granada: Comares, 2002.

JESTAEDT, Matthias. La teoria de la ponderación: sus fortalezas y debilidades. Trad. Irgmard Kleine. In: MONTEALEGRE, Eduardo (coord.). La ponderación em el derecho. Bogotá: Universidad Externado de Colombia, 2008.

JUAN MORESO, José. Alexy y la aritmética de la ponderación. In: CARBONELL, Miguel; GRÁNDEZ CASTRO, Pedro P. (coord.). El principio de proporcionalidad en el derecho contemporáneo. Lima: Palestra, 2010.

KANT, Immanuel. A metafísica dos costumes. Trad. Edson Bini. Bauru, SP: EDIPRO, 2003.

. Fundamentación de la metafísica de las costumbres. Trad. Manuel G. Morente. Madrid: Calpe, 1921.

KAUFMAN, Whitley R. P. Honor and revenge: a theory of punishment. Dordrecht: Springer, 2013.

KAUFMANN, Arthur; HASSEMER, Winfried. Introdução à filosofia do direito e à teoria do direito. Lisboa: Fundação Calouste Gulbenkian, 2002. 
KELSEN, Hans. Teoria geral do direito e do Estado. Trad. Luís Carlos Borges. 3. ed. São Paulo: Martins Fontes, 1998.

Teoria pura do direito. Trad. João Baptista Machado. 6. ed. São Paulo: Martins Fontes, 1998.

. Teoria pura do direito. Trad. João Baptista Machado. 5. ed. São Paulo: Martins Fontes, 1996.

KELSEN, Hans; BOBBIO, Norberto et al. Crítica del derecho natural. Madrid: Taurus, 1966.

KENNEDY, Duncan. Formalismo jurídico. Trad. Sheila Stolz. In: RODRIGUEZ, José Rodrigo (org.). A justificação do formalismo jurídico - textos em debate. São Paulo: Saraiva, 2011.

KINDERMANN, Harald. Alibigesetzgebung als symbolische Gesetzgebung. In: VOIGT, Rüdiger (org.). Symbole der Politik, Politik der Symbole. Opladen: Leske, Budrich, 1989.

KINDHÄUSER, Urs. Retribución de culpabilidad y pena. Trad. Nuria Pastor. In: KINDHÄUSER, Urs; MAÑALICH, Juan Pablo. Pena y culpabilidad en el Estado democrático de derecho. Buenos Aires: Editorial B de F, 2011.

KÜHL, Kristian. Direito penal fragmentário e subsidiário. Trad. Pedro Ferreira Leite Neto. In: OLIVEIRA, William Terra de; LEITE NETO, Pedro Ferreira; ESSADO, Tiago Cintra; SAAD-DINIZ, Eduardo. Direito penal econômico: estudos em homenagem aos 75 anos do Professor Klaus Tiedemann. São Paulo: LiberArs, 2013.

KLUG, Ulrich. Despedida de Kant y Hegel (una crítica jusfilosófica básica). Trad. Jorge M. Seña. In: KLUG, Ulrich. Problemas de la filosofía y de la pragmática del derecho. México, DF: Distribuciones Fontamara, 1992.

. Para una crítica de la filosofía penal de Kant y Hegel. Trad. Enrique Bacigalupo. In: BAUMANN, Jürgen; HENTIG, Hans von; KLUG, Ulrich et al. Problemas actuales de las ciencias penales y la filosofía del derecho en homenaje al profesor Luis Jiménez de Asúa. Buenos Aires: Ediciones Pannedille, 1970.

KRÜGER, Herbert. Allgemeine staatslehre. Stuttgart, Berlin, Köln, Mainz: W. Kohlhammer Verlag, 1966.

KUHLEN, Lothar. Anmerkungen zum Verhältnis von Strafrecht und Verfassungsrecht. In: ANDRADE, Manuel da Costa; ANTUNES, Maria João; SOUSA, Susana Aires de. Estudos em homenagem ao Prof. Doutor Jorge de Figueiredo Dias, vol. I. Coimbra: Coimbra Editora, 2009.

KUMM, Mattias. Mas allá del principio de proporcionalidad: el pluralismo estructural de los derechos fundamentales en el derecho de los constitucionales de los Estados Unidos. Trad. Daniel OliverLalana. In: SIECKMANN, Jan-R. (ed.). La teoría principialista de los derechos fundamentales: estudios sobre la teoría de los derechos fundamentales de Robert Alexy. Madrid: Marcial Pons, 2011, p. 273-296.

LAGODNY, Otto. El derecho penal sustantivo como piedra de toque de la dogmática constitucional. Trad. Íñigo Ortiz de Urbina Gimeno. In: HEFENDEHL, Roland [ed]. La teoría del bien jurídico: ¿Fundamento de legitimación del derecho penal o juego de abalorios dogmático? Madrid: Marcial Pons, 2007.

LAMARCA PÉREZ, Carmen. El principio de proporcionalidad y el control constitucional de las leyes penales. Madrid: Colex, 2011.

LARENZ, Karl. Metodologia da ciência do direito. Trad. José Lamargo. 3. ed. Lisboa: Fundação Calouste Gulbenkian, 1997.

LASSALLE, Ferdinand. $O$ que é uma Constituição? Trad. Hiltomar Martins Oliveira. Belo Horizonte: Cultura Jurídica, 2004. 
LOPERA MESA, Gloria Patricia. El principio de proporcionalidad y los dilemas del constitucionalismo. Revista Española de Derecho Constitucional, Madrid: Centro de Estudios Políticos y Constitucionales, ano 25, n. 73, jan.-abr., 2005.

. Posibilidades y límites del principio de proporcionalidad como instrumento de control del legislador penal. In: MIR PUIG, Santiago; QUERALT JIMÉNEZ, Joan J. (dir.). Constitución y principios del Derecho Penal: algunas bases constitucionales. Valencia: Tirant lo Blanch, 2010.

. Principio de proporcionalidad y ley penal: bases para un modelo de control de constitucionalidad de las leyes penales. Madrid: Centro de Estudios Políticos y Constitucionales, 2006.

. Proporcionalidad de las penas y principio de proporcionalidad en Derecho Penal. Jueces Para la Democracia, Madrid, n. 70, mar. 2011.

LOPES, Mauricio Antonio Ribeiro. O princípio da proporcionalidade no direito penal econômico. In: PODVAL, Roberto (org.). Temas de direito penal econômico. São Paulo: Editora Revista dos Tribunais, 2000.

LUHMANN, Niklas. El derecho como sistema social. Trad. Carlos Gómez-Jara Díez. In: GÓMEZ-JARA DÍEZ, Carlos (ed.). Teoría de sistemas y derecho penal. Granada: Comares, 2005.

. El derecho de la sociedad. Trad. Javier Torres Nafarrete. 2. ed. Ciudad de México: Herder, 2005.

LUHMANN, Niklas. Grundrechte als Institution: ein Beitrag zur politischen Soziologie. Berlim: Duncker \& Humblot, 1974.

. La differenziazione del diritto. Contributti ala sociologia e ala teoria del diritto. Milão: Società Editrice Il Mulino, 1990.

. La sociedad de la sociedad. Trad. Javier Torres Nafarrete. Ciudad de México: Herder, 2006.

. Legitimação pelo procedimento. Trad. Maria Conceição Côrte-Real. Brasília: Editora Universidade de Brasília, 1980.

. Operational closure and structural coupling the differentiation of the legal system. Cardoso Law Review, n. 13, 1992.

. Quod omnes tangit: remarks on Jürgen Habermas legal theory. Trad. Mike Robert Horenstein. In: ROSENFIELD, Michel; ARATO, Andrew (ed.). Habermas on law and democracy: critical exchanges. Berkeley e Los Angeles: University of California Press, 1986.

. Sistemas sociales: lineamientos para una teoría general. Trad. Silvia Pappe e Brunhilde Erker. Coord. Javier Torres Nafarrate. Barcelona: Anthropos; México: Universidad Iberoamericana, 1998.

. Sociología del riesgo. Trad. Silvia Pappe, Brunhilde Erker e Luis Felipe Segura. 3. ed. México-DF: Universidad Iberoamericana, 2006.

. Sociologia do Direito I. Trad. Gustavo Bayer. Rio de Janeiro: Edições Tempo Brasileiro, 1983.

. Sociologia do Direito II. Trad. Gustavo Bayer. Rio de Janeiro: Edições Tempo Brasileiro, 1985.

. The self-reproduction of law and its limits. In: TEUBNER, Gunther (ed.). Dilemmas of law in the welfare sate. Berlim, Nova York: Walter de Gruyter, 1988.

. Verfassung als evolutionäre Errungenschaft. In: Rechtshistorisches Journal, 9, Frankfurt am Main: Löwenklau.

LUÑO PEÑA, Enrico. Derecho natural. Barcelona: Librería La Hormiga de Oro, 1961.

LUZ, Yuri Corrêa da. Entre bens jurídicos e deveres normativos: um estudo sobre os fundamentos do direito penal contemporâneo. São Paulo: IBCCRIM, 2013. 
LUZON PEÑA, Diego-Manuel. La relación del merecimento de pena y de la necesidad de pena con la estructura del delito. In: SILVA SÁNCHEZ, Jesús-María; SCHÜNEMANN, Bernd; DIAS, Jorge de Figueiredo (coord..). Fundamentos de un sistema europeo del derecho penal. Barcelona: J. M. Bosch Editor, 1995.

MACCORMICK, Neil. Direito, interpretação e razoabilidade. In: MACEDO JÚNIOR, Ronaldo Porto; BARBIERI, Catarina Helena Cortada. Direito e interpretação: racionalidade e instituições. São Paulo: Saraiva, 2011.

MANCILLA, Nathaly. La constitución (chilena) y los derechos fundamentales ante los intentos desdiferenciadores de la política. In: CADENAS, Hugo; MASCAREÑO, Aldo; URQUIZA, Anahí (ed.). Niklas Luhmann y el legado universalista de su teoría: aportes para el análisis de la complejidad social contemporánea. Santiago: RIL Editores, 2012.

MARCUSE, Herbert. Razão e revolução: Hegel e o advento da teoria social. Trad. Marília Barroso. São Paulo: Paz e Terra, 2004.

MARTÍNEZ GARCÍA, Jesús Ignacio. La validez en la teoría de Luhmann. In: RAMOS PASCUA, José Antonio; RODILLA GONZÁLEZ, Miguel Ángel (ed.). El positivismo jurídico a examen: estudis en homenaje a José Delgado Pinto. Salamanca: Aquilafuente, Ediciones Universidad de Salamanca, 2006.

MARTÍNEZ ZORRILLA, David. Conflictos constitucionales, ponderación e indeterminación normativa. Tese de doutoramento apresentada à Faculdade de Direito da Universidade de Pompeu Fabra. Barcelona: 2004.

MARTÍNEZ-BUJÁN PÉREZ, Carlos. Algunas reflexiones sobre la moderna teoría del big crunch en la selección de bienes jurídico-penales (especial referencia al ámbito económico). In: PORTILLA CONTRERAS, Guillermo. Mutaciones de Leviatán: legitimación de los nuevos modelos penales. Madrid: Ediciones Akal, Universidad Internacional de Andalucía, 2005.

MASSUD, Leonardo. Da pena e sua fixação: finalidades, circunstâncias judiciais e apontamentos para o fim do mínimo legal. São Paulo: DPJ Editora, 2009.

MATHIS, Klaus. Efficiency instead of justice? Searching for the philosophical foundations of the economic analysis of law. Trad. Deborah Shannon. Dordrecht: Springer, 2009.

MAURACH, Reinhart. Derecho penal: parte general, v. 1. Teoría general del derecho penal y estructura del hecho punible. Trad. Jorge Bofill Genzch e Enrique Aimone Gibson. Buenos Aires: Editorial Astrea de Alfredo y Ricardo Depalma, 1994.

MAYER, Max Ernst. Derecho penal, Parte General. Trad. Sergio Politoff Lipschitz. Montevideo: Editorial B de F; Buenos Aires: Euros Editores, 2007.

MENDES, Conrado Hübner. Direitos fundamentais, separação de poderes e deliberação. Tese de Doutoramento apresentada perante a Faculdade de Filosofia, Letras e Ciências Humanas da Universidade de São Paulo. São Paulo, 2008.

. Direitos fundamentais, separação de poderes e deliberação. São Paulo: Saraiva, 2011.

. Onze ilhas. Folha de S. Paulo, São Paulo, 01 Fev. 2010. Tendências e debates. Disponível em: < http://www1.folha.uol.com.br/fsp/opiniao/fz0102201008.htm>. Acesso em: 02 Mar. 2015.

MENDES, Gilmar. O princípio da proporcionalidade na jurisprudência do Supremo Tribunal Federal: novas leituras. Revista Diálogos Jurídicos, Salvador, Ano I, vol. I, n. 5, ago. 2001, p. 2. Disponível em: < http://www.direitopublico.com.br/pdf_5/dialogo-juridico-05-agosto-2001-gilmarmendes.pdf>. Acesso em: 15 Jul. 2013. 
MEZGER, Edmund. Tratado de derecho penal, tomo II. Trad. José Arturo Rodriguez Muñoz. 3. ed. Madrid: Editorial Revista de Derecho Privado, 1933.

MILLÁN, René. Sociedad compleja: ¿cómo se integra? Desacatos, n. 28, set.-dez. 2008.

MIR PUIG, Santiago. Bases constitucionales del derecho penal. Madrid: Iustel, 2011.

. El principio de proporcionalidad como fundamento constitucional de límites materiales del Derecho penal. In: CARBONELL MATEU, Juan Carlos; GONZÁLEZ CUSSAC, José Luis; ORTS BERENGUER, Enrique. Constitución, derechos fundamentales y sistema penal: semblanzas y estudios con motivo del setenta aniversario del profesor Tomás Vives Antón, tomo II. Coordenação a cargo de María Luisa Cuerda Arnau. Valencia: Tirant lo Blanch, 2009.

Introducción a las bases del derecho penal: concepto y método. 2. ed. Buenos Aires: Editorial B de F, 2003.

MOCCIA, Sergio. Il diritto penale tra essere e valore: funzione dela pena e sistemática teleológica. Napoli: Edizioni Scientifiche Italiane, 1992.

MOORE, Michael S. Libertad y drogas. In: GREIFF, Gustavo de; GREIFF, Pablo de (org.). Moralidad, legalidad y drogas. Trad. Gustavo de Greiff. México: Fondo de Cultura Económica, 2000.

MORALES PRATS, Fermin. Adecuación social y tutela penal del honor: perspectiva despenalizadora. Cuadernos de política criminal, Madrid: Edersa, n. 36, 1988.

MOURA, Maria Thereza Rocha de Assis. O IBCCRIM e a inconstitucionalidade da proibição de progressão nos crimes hediondos. Boletim IBCCRIM, São Paulo: IBCCRIM, Edição Especial, v. 20, 2012.

MUELLBAUER, John. Professor Sen on the standard of living. In: HAWTHORN, Geoffrey (ed.). The standard of living: Tanner lectures. Cambridge: Cambridge University Press, 2001.

MUÑOZ CONDE, Francisco. De nuevo sobre el "Derecho penal del enemigo". Buenos Aires: Hamurabi, 2005.

. Dogmática jurídico penal y política criminal: una relación conflictiva, pero necesaria. Revista Brasileira de Ciências Criminais, São Paulo: Editora Revista dos Tribunais, ano 21, v. 105, nov.dez. 2013.

Edmund Mezger y el derecho penal de su tiempo: estudios sobre el derecho penal en el nacionalsocialismo. 4. ed. Valencia: Tirant lo Blanch, 2003.

Introducción al derecho penal. 2. ed. Buenos Aires, Montevidéu: Editorial B de F, 2001.

. La generalización del derecho penal de excepción: tendencias legislativas y doctrinales: entre la tolerancia cero y el derecho penal del enemigo. In: CAMPO MORENO, Juan Carlos; GONZÁLEZ CUSSAC, José Luis (dir.). La generalización del derecho penal de excepción: tendencias legislativas. Estudios de Derecho Judicial128. Madrid: CGOJ, 2007.

NAVARRO FRÍAS, Irene. El principio de proporcionalidad en sentido estricto: ¿principio de proporcionalidad entre el delito y la pena o balance global de costes y beneficios? In: LASCURAÍN SÁNCHEZ, Juan Antonio; RUSCONI, Maximiliano (dir.). El principio de proporcionalidad penal. Buenos Aires: Editorial Ad Hoc, 2014.

. Técnica legislativa y derecho penal. Estudios Penales y Criminológicos, vol. XXX, 2010.

NEUMANN, Ulfrid. O princípio da proporcionalidade como princípio limitador da pena. Trad. Antonio Martins. Revista de Brasileira de Ciências Criminais, São Paulo: Editora Revista dos Tribunais, ano 16, n. 71, p. 205-232, mar.-abr., 2008. 
NEVES, Marcelo. A constitucionalização simbólica. São Paulo: Editora Acadêmica, 1994.

. A força simbólica dos direitos humanos. Revista Eletrônica de Direito do Estado, Salvador, n. 4, out.-dez. 2005, p. 3. Disponível em: <http://www.direitodoestado.com/revista/rede-4-outubro-2005Marcelo\%20Neves.pdf $>$. Acesso em: 20 Mar. 2014.

. Del pluralismo jurídico a la miscelânea social: el problema de la falta de identidad de la(s) esfera(s) de juridicidad en la modernidad periférica y sus implicaciones en América Latina. Série J. Enseñanza del derecho y material didáctico - Instituto de Investigaciones Jurídicas. UNAM, México, 1995, n. 1.

. Entre Hidra e Hércules: princípios e regras constitucionais. São Paulo: Editora WMV Martins Fontes, 2013.

. Entre Têmis e Leviatã: uma relação difícil: o Estado Democrático de Direito a partir e além de Luhmann e Habermas. Trad. pelo próprio autor. 2. ed. São Paulo: Martins Fontes, 2008.

. From the autopoiesis to the allopoiesis of law. Trad. Margaret Griesse e Jeffrey Hoff. Journal of Law and Society, Oxford: Blackwell Publishers, v. 28, n. 2, jun. 2001.

. Luhmann, Habermas e o estado de direito. Lua Nova, São Paulo, n. 37, 1996.

. Transconstitucionalismo. São Paulo: Editora WMF Martins Fontes, 2009.

OLIVEIRA, Ana Carolina Carlos de. Hassemer e o direito penal brasileiro: direito de intervenção, sanção penal e administrativa. São Paulo: Instituto Brasileiro de Ciências Criminais, 2013.

PALAZZO, Francesco C. Valores constitucionais e direito penal: um estudo comparado. Trad. Gérson Pereira dos Santos. Porto Alegre: Sergio Antonio Fabris Editor, 1989.

PALMA, Juliana Bonacorsi de; FEFERBAUM, Marina; PINHEIRO, Victor Marcel. Meu trabalho precisa de jurisprudência? Como utilizá-la? In: QUEIROZ, Rafael Mafei Rabelo; FEFERBAU, Marina (coord.). Metodologia jurídica: um roteiro prático para trabalhos de conclusão e curso. São Paulo: Saraiva, 2012.

PATEMAN, Carole. Participação e teoria democrática. Trad. Luiz Paulo Rouanet. Rio de Janeiro: Paz e Terra, 1992.

PAVARINI, Massimo. Gobierno del miedo o a través del miedo? In: Máximo Sozzo (org.). Por una sociología crítica del control social: ensayos en honor a Juan S. Pegoraro. Ciudad Autónoma de Buenos Aires: Del Puerto, 2010.

PAWLIK, Michael. Hegel e a racionalidade do real. Trad. Eduardo Saad-Diniz. In: PAWLIK, Michael. Teoria da ciência do direito penal, filosofia e terrorismo. Organização e tradução Eduardo SaadDiniz. São Paulo: LiberArs, 2012.

. O passo mais importante da dogmática da última geração? Reflexões para a diferenciação entre injusto e culpabilidade em direito penal. Trad. Eduardo Saad-Diniz. In: PAWLIK, Michael. Teoria da ciência do direito penal, filosofia e terrorismo. Organização e tradução Eduardo Saad-Diniz. São Paulo: LiberArs, 2012.

. O terrorista e o direito dele: sobre a posição teórico-jurídica do terrorismo moderno. Trad. Eduardo Saad-Diniz. In: PAWLIK, Michael. Teoria da ciência do direito penal, filosofia e terrorismo. Organização e tradução Eduardo Saad-Diniz. São Paulo: LiberArs, 2012.

. Teoria da ciência do direito penal, filosofia e terrorismo. Trad. Eduardo Saad-Diniz. São Paulo: LiberArs, 2012.

PEÑARANDA RAMOS, Enrique; SUÁREZ GONZÁLEZ, Carlos J.; CANCIO MELÍA, MANUEL. Consideraciones sobre la teoría de la imputación de Günther Jakobs. In: JAKOBS, Günther. Estudios 
de derecho penal. Trad. Enrique Peñaranda Ramos, Carlos J. Suárez Gonzáles e Manuel Cancio Melía. Madrid: Editorial Civitas, 1997.

PEREIRA, Bruno Ramos. O uso da proporcionalidade no Supremo Tribunal Federal - Análise dos votos do ministro Gilmar Mendes (2004-2006). Tese USP. São Paulo, 2009.

PÉREZ PINZÓN, Álvaro Orlando. El funcionalismo en la sociología actual. In: MONTEALEGRE LYNETT, Eduardo (coord.). El funcionalismo en derecho penal: libro homenaje al Profesor Günther Jakobs. Bogotá: Universidad Externado de Colombia, 2003.

PEREZ, Oren. Law as a strange loop. In: CALLIESS, Gralf-Peter; FISCHER-LESCANO, Andreas; WIELSCH, Dan. Soziologische Jurisprudenz: festschrift für Günther Teubner zum 65. Geburtstag. Berlin: De Gruyter Recht, 2009.

PESTANA, Débora Regina. Cultura do medo: reflexões sobre violência criminal, controle social e cidadania no Brasil. São Paulo: Editora Método, 2003.

PINTO, Ronaldo Batista. A colaboração premiada da Lei $\mathrm{n}^{\circ}$ 12.850/2013. Revista Magister de Direito Penal e Processual Penal, São Paulo: Editora Magister, Ano X, n. 56, out.-nov. 2013.

PIRES, Álvaro. A racionalidade penal moderna, o público e os direitos humanos. Revista Novos Estudos CEBRAP, n. 68, São Paulo: CEBRAP, 2004.

PLATÃO. As leis, ou da legislação e epinomis. Trad. Edson Bini. Bauru, SP: Edipro, 1999.

POLAINO NAVARRETE, Miguel. Metódica jurisprudencial en el derecho penal. In: POLAINO NAVARRETE, Miguel. Estudios penales. Córdoba: Universidad de Córdoba, 1998.

POLAINO-ORTS, Miguel. Comunicação versus coação? Considerações críticas sobre a pretendida cisão da função da pena. Trad. Eduardo Saad-Diniz. In: POLAINO-ORTS, Miguel; SAAD-DINIZ, Eduardo (org.). Teoria da pena, bem jurídico e imputação. São Paulo: LiberArs, 2012.

. Derecho penal del enemigo: fundamentos, potencial de sentido y límites de vigencia. Barcelona: Bosch, 2009.

. Discriminación positiva y violência contra la mujer. La legitimación de un enemigo de género. In: POLAINO-ORTS, Miguel; UGAZ HEUDEBERT, Juan Diego. Feminicidio y discriminación positiva em derecho penal. Lima: ARA Editores, 2012.

. Realidad y ficción en el derecho penal del enemigo. In: ANDRADE, Manuel da Costa; ANTUNES, Maria João; SOUSA, Susana Aires de. Estudos em homenagem ao Prof. Doutor Jorge de Figueiredo Dias, v. 1. Coimbra: Coimbra Editora, 2009.

. Vigencia de la norma: el potencial de sentido de un concepto. In: MONTEALEGRE LYNETT, Eduardo. El funcionalismo en derecho penal: libro homenaje al Profesor Günther Jakobs, tomo II. Bogotá: Universidad Externado de Colombia, 2003.

. Vigencia de la norma: el potencial de sentido de um concepto. In: JAKOBS, Günther; POLAINO NAVARRETE, Miguel; POLAINO-ORTS, Miguel (org.). Bien jurídico, vigência de la norma y daño social. Lima: Ara Editores, 2010.

POPPER, Karl. A sociedade aberta e seus inimigos, vol. 2. Trad. Milton Amado. Belo Horizonte: Editora Itatiaia; São Paulo: Editora Universidade de São Paulo, 1974.

POSCHER, Ralf. Aciertos, errores y falso autoconcepto de la teoría de los principios. Trad. Daniel OliverLalana. In: SIECKMANN, Jan-R. (ed.). La teoría principialista de los derechos fundamentales: estudios sobre la teoría de los derechos fundamentales de Robert Alexy. Madrid: Marcial Pons, 2011. 
POTTER, Nelson. Kant on punishment. In: HILL JR., Thomas E (ed.). The Blackwell guide to Kant's ethics. Chichester: Wiley-Blackwell, 2009.

PRADO, Geraldo. Justiça penal consensual. Discursos sediciosos: crime, direito e sociedade, n. 9/10, v. 5, 2000.

PRIETO NAVARRO, Evaristo. Sobre los límites y posibilidades de la respuesta jurídica al riesgo. In: DA AGRA, Cândido; DOMÍNGUEZ, José Luis; GARCÍA AMADO, Juan Antonio et al. (eds.). La seguridad en la sociedad del riesgo: um debate abierto. Barcelona: Atelier, 2003.

. Teoría de sistemas, funciones del derecho y control social. Perspectivas e imposibilidades para la dogmática penal. Doxa: Cuadernos de Filosofía del Derecho, n. 23, 2000.

PRIETO SANCHÍS, Luis. El juicio de ponderación constitucional. In: CARBONELL, Miguel; GRÁNDEZ CASTRO, Pedro P. (coord.). El principio de proporcionalidad en el derecho contemporáneo. Lima: Palestra Editores, 2010.

. La filosofía penal de la ilustración. Talplan, México: Instituto Nacional de Ciencias Penales, 2003.

PRITWITZ, Cornelius. La función del derecho penal en la sociedad del riesgo - defensa de um rol necesariamente modesto. In: AMBOS, Kai (dir.); BÖHM, María Laura (coord.). Desarrollos actuales de las ciencias criminales en Alemania. Bogotá: Editorial Temis, 2012.

PUPPE, Ingeborg. Ciência do direito penal e jurisprudência. Trad. Luis Greco. Revista Brasileira de Ciências Criminais, São Paulo: Editora Revista dos Tribunais, ano 14, n. 58, p. 105-113, jan.-fev., 2006.

. La distinción entre dolo e imprudencia: comentario al §15 del Código Penal alemán. Trad. Marcelo A. Sancinetti. Buenos Aires: Hammurabi, 2010.

QUINTERO OLIVARES, Gonzalo. El problema penal: la tensión entre teoría y praxis en el derecho penal. Madrid: Iustel, 2012.

. Parte general del derecho penal. Cizur Menor, Navarra: Editorial Arazandi, 2005.

RADBRUCH, Gustav. Introducción a la filosofía del derecho. Trad. Wenceslao Roces. México: Fondo de Cultura Económica, 1951.

RAMOS, Elival da Silva. A exigência de proporcionalidade no controle abstrato de normas brasileiro. Revista Mestrado em Direito - Direitos Humanos Fundamentais, Osasco-SP: Edifieo, ano 10, n. 1, jan.-jun. 2010.

RASCOVSKI, Luiz. A (in)eficiência da delação premiada. In: INSTITUTO DE ESTUDOS AVANÇADOS DE PROCESSO PENAL - ASF. Estudos de processo penal. São Paulo: Scortecci, 2011.

RAUPP, Mariana; BENEDETTI, Juliana Cardoso. A implementação da justiça restaurativa no Brasil: uma avaliação dos programas de justiça restaurativa de São Caetano do Sul, Brasília e Porto Alegre. Revista Ultima Ratio, Rio de Janeiro: Editora Lumen Juris, ano 1, n. 1, 2007.

REAL ALCAL, J. Alberto del. Sobre la indeterminación del derecho y la ley constitucional: el término "nacionalidades" como concepto jurídico indeterminado. Foro - Revista de Derecho, n. 2, 20032004.

REALE JUNIOR, Miguel. Anti-semitismo é racismo. Revista Brasileira de Ciências Criminais, São Paulo: Editora Revista dos Tribunais, n. 43, ano 11, abr.-jun. 2003.

Instituições de direito penal, parte geral. 3. ed. Rio de Janeiro: Forense, 2009.

REALE, Miguel. Filosofia do direito. 19 ed. São Paulo: Saraiva, 1999. 
RISTROPH, Alice. Proportionality as a principle of limited government. Duke Law Jorunal , Durham: Duke University School of Law, 2005, vol. 55.

RIVERA BEIRAS, Iñaki (coord.). Política criminal y sistema penal: viejas e nuevas racionalidades punitivas. Barcelona: Anthropos, 2005.

ROBERTS, Paul Craig; STRATTON, Lawrence M. The tyranny of good intentions: how prosecutors and bureaucrats are trampling the constitution in the name of justice. Roseville: Forum, 2000.

ROBINSON, Paul H. Principios distributivos del derecho penal: a quién debe sancionarse y en qué medida. Trad. Manuel Cancio e Iñigo Ortiz de Urbina. Madrid: Marcial Pons, 2012.

RODRIGO, José Rodriguez. Prefácio. "Quanto terá sido o óbvio...”: o debate sobre o formalismo em textos escolhidos. In: RODRIGO, José Rodriguez. (org.). A justificação do formalismo jurídico: textos em debate. São Paulo: Saraiva, 2011.

RODRÍGUEZ MANSILLA, Darío Rodríguez; RÍOS F., René. Las organizaciones sociales en una sociedad compleja. Perspectivas CEES-UC, Santiago, n. 2, jul. 2007, p. 11. Disponível em: < http://emprendimientossolidarios.uc.cl/download/Perspectivas_CEES-UC-2.pdf>. Acesso em: 29 Mar. 2014.

RODRÍGUEZ MANSILLA, Darío Rodríguez; TORRES NAFARRATE. Autopoiesis, la unidad de una diferencia: Luhmann y Maturana. Sociologias, Porto Alegre, ano 5, nº. 9, jan.-jun. 2003.

RODRÍGUEZ MANSILLA, Darío. Invitación a la sociología de Niklas Luhmann. In: LUHMANN, Niklas. El derecho de la sociedad. Trad. Javier Torres Nafarrete. 2. ed. Ciudad de México: Herder, 2005.

RODRIGUEZ, José Rodrigo. A persistência do formalismo: uma crítica para além da separação de poderes. In: RODRIGUEZ, José Rodrigo; SILVA E COSTA, Carlos Eduardo Batalha; BARBOSA, Samuel Rodrigues (org.). Nas fronteiras do formalismo. São Paulo: Saraiva, 2010.

RODRÍGUEZ, Víctor Gabriel. Fundamentos de direito penal brasileiro: lei penal e teoria geral do crime. São Paulo: Atlas, 2010.

. Liberdade, injusto massacre da imprensa e algum testemunho pessoal. In: PEDRINA, Gustavo Mascarenhas Lacerda (org.). AP 470: análise da mídia no julgamento do mensalão a partir de entrevistas com a defesa. São Paulo: LiberArs, 2013.

. Notas sobre a insuficiência da interpretação exclusivamente constitucional do direito penal. BEÇAK, Rubens; POVEDA VELASCO, Ignácio Maria [org.]. $O$ direito e o futuro da pessoa: estudos em homenagem ao professor Antonio Junqueira de Azevedo. São Paulo: Atlas, 2011.

ROMEO CASABONA, Carlos María. El "principio de precaución” en derecho penal. Iter Criminis: Revista de Ciencias Penales, n. 9, 2004.

ROXIN, Claus. Derecho penal, parte general, tomo. Fundamentos. La estrutura de la teoría del delito. Trad. Diego-Manuel Luzón Peña, Miguel Díaz y García Conlledo e Javier de Vicente Remesal. 2. ed. Madrid: Editorial CIvitas, 1997.

. El significado de la política criminal para los fundamentos sistemáticos del Derecho penal. In: ROXIN, Claus; POLAINO NAVARRETE, Miguel; POLAINO-ORTS, Miguel (org.). Política criminal y dogmática penal: cuestiones fundamentales. Lima: Aras Editores, 2013.

. Estudos de direito penal. Trad. Luís Greco. Rio de Janeiro: Renovar, 2006.

. Política criminal e sistema jurídico-penal. Trad. Luís Greco. Rio de Janeiro: Renovar, 2002.

. Sobre la autoría y participación en el derecho penal. In: BAUMANN, Jürgen; HENTIG, Hans von; KLUG, Ulrich et al. Problemas actuales de las ciencias penales y la filosofía del derecho en homenaje al profesor Luis Jiménez de Asúa. Buenos Aires: Ediciones Pannedille, 1970. 
Teoría del tipo penal: tipos abiertos y elementos del deber jurídico. Trad. Enrique Bacigalupo. Buenos Aires: Ediciones Depalma, 1979.

SAAD-DINIZ, Eduardo, A sociologia da decisão: a econômica, a política, a jurídica. Revista da Faculdade de Direito da USP, São Paulo, v. 102, jan.-dez. 2007.

. Fronteras del normativismo: a ejemplo de las funciones de la información en los programas de criminal compliance. Revista da Faculdade de Direito da Universidade de São Paulo, São Paulo, v. 108, jan.-dec., 2013.

. Inimigo e pessoa no direito penal. São Paulo: LiberArs, 2012.

. Notas sobre a intervenção da mídia no livre conhecimento e o papel do "novo defensor penal". In: PEDRINA, Gustavo Mascarenhas Lacerda. AP 470: análise da intervenção da mídia no julgamento do mensalão a partir de entrevistas com a defesa. São Paulo: LiberArs, 2013.

. Regras de proporcionalidade e oportunidade na interpretação penal. In: OLIVEIRA, William Terra de; LEITE NETO, Pedro Ferreira; ESSADO, Tiago Cintra; SAAD-DINIZ, Eduardo. Direito penal econômico: estudos em homenagem aos 75 anos do Professor Klaus Tiedemann. São Paulo: LiberArs, 2013.

SAFATLE, Vladimir. Grande hotel abismo: por uma reconstrução da teoria do reconhecimento. São Paulo: Martins Fontes, 2012.

SALLA, Fernando. O RDD é temido, mas confere prestígio aos que passam por ele. Estado de S. Paulo, Caderno Aliás, 20 Ago. 2006.2 Disponível em: $<$ http://www.nevusp.org/portugues/index.php?option=com_content\&task=view \&id=128\&Itemid=29 >. Acesso em: 20 Dez. 2014.

SALVADOR NETTO, Alamiro Velludo. Direito penal e propriedade privada: a racionalidade do sistema penal na tutela do patrimônio. Tese de Livre-Docência apresentada à Faculdade de Direito da Universidade de São Paulo. São Paulo, 2013.

. Finalidades da pena: conceito material de delito e sistema penal integral. São Paulo: Quartier Latin, 2009.

SANTOS, Boaventura de Sousa. Pela mão de Alice: o social e o político na pós-modernidade. 7. ed. Porto: Edições Afrontamento, 1999.

SARCEDO, Leandro. Política criminal e crimes econômicos. São Paulo: Alameda, 2012.

SARLET, Ingo Wolfgang. Constituição e proporcionalidade. Revista Brasileira de Ciências Criminais, São Paulo: Editora Revista dos Tribunais, v. 12, n. 47, mar.-abr. 2004.

SARMENTO, Daniel. Direitos fundamentais e relações privadas. 2. ed. Rio de Janeiro: Lumen Juris, 2006.

. Liberdade de expressão, pluralismo e o papel promocional do Estado. Revista Diálogo Jurídico, Salvador, n. 16, mai.-ago. 2007, p. 20. Disponível em: <http://www.direitopublico.com.br>. Acesso em: 20 Mar. 2014.

SCHAUER, Frederick. Formalismo. Trad. Diego Werneck Arguelhes, Fábio Shecaira e Noel Struchiner. In: RODRIGUEZ, José Rodrigo (org.). A justificação do formalismo jurídico - textos em debate. São Paulo: Saraiva, 2011.

SCHECAIRA, Sérgio Salomão. Sistema de garantias e o direito penal juvenil. São Paulo: Editora Revista dos Tribunais, 2008.

SCHILD, Wolfgang. Funktionale und nicht-funktionale Bedeutung des Gesetzes: einige Anmerkungen zur Gesetzgebungslehre am Beispiel des materiellen Strafrechts. In: TAMMELO, Ilmar; MOCK, Erhard 
(org.). Rechtstheorie und Gesetzgebung: Festschrift für Robert Weimar. Frankfurt am Main, Berna, Nova York: Verlag Peter Lang, 1986.

SCHMITT, Carl. O conceito do político. Teoria do Partisan. Trad. Geraldo de Carvalho. Belo Horizonte: Del Rey, 2008.

. Sobre los tres modos de pensar la ciencia jurídica. Trad. Montserrat Herrero. Madrid: Editorial Tecnos, 1996, p. 9-44. Isso apontaria para um sincretismo entre normativismo e decisionismo, culminando no preenchimento político do campo normativo.

. Teología política: cuatro ensayos sobre la soberanía. Trad. Francisco Javier Conde. Buenos Aires: Editorial Struhart \& Cía.

. Teoría de la constitución. Trad. Francisco Ayala. Madrid: Alianza Editorial, 1996.

SCHROEDER, Friedrich-Christian. A renúncia à sanção no direito alemão.Trad. Gustavo de Carvalho Marin, com revisões de José Roberto Macri Júnior. In: SCHROEDER, Friedrich-Christian. Autoria, imputação e dogmática aplicada no direito penal. Eduardo Saad-Diniz, Andrés Falcone, Gustavo de Carvalho Marin (org.). São Paulo: LiberArs, 2013.

. A revolução do direito penal sexual (1992-1998). In: SCHROEDER, Friedrich-Christian. Autoria, imputação e dogmática aplicada no direito penal. Eduardo Saad-Diniz, Andrés Falcone e Gustavo de Carvalho Marin (org.). São Paulo: LiberArs, 2013.

SCHULTE, Phillip H. Terrorismus und Anti-Terrorismus-Gesetzgebung: eine rechtssoziologische Analyse. Münster, Nova York, Munique, Berlim: Waxmann, 2008.

SCHÜNEMANN, Bernd. El principio de protección de bienes jurídicos como punto de fuga de los límites constitucionales de los tipos penales y de su interpretación. Trad. María Martín Lorenzo y Mirja Feldmann. In: HEFENDEHL, Roland [ed]. La teoría del bien jurídico: ¿fundamento de legitimación del derecho penal o juego de abalorios dogmático? Madrid: Marcial Pons, 2007.

SEIBEL, Sergio. A Lei 11.343/2006 sobre drogas e o impacto na saúde pública. Boletim IBCCRIM, São Paulo: IBCCRIM, ano 20, Edição Especial sobre Drogas, out. 2012.

SELLTIZ, C.; JAHODA, M.; DEUTSCH, M.; COOK, S. M. Métodos de pesquisa das relações sociais. São Paulo: Editora da Universidade de São Paulo, 1965.

SEN, Amartya The standard of living: lecture II, lives and capabilities. In: HAWTHORN, Geoffrey (ed.). The standard of living: Tanner lectures. Cambridge: Cambridge University Press, 2001.

. Desenvolvimento como liberdade. Trad. Laura Teixeira Motta. São Paulo: Companhia das Letras, 2000.

. The standard of living. The Tanner Lecutres on Human Values, Cambridge University, Mar 12. 1985, p. 37-38 e 48-50. Disponível em: <http://tannerlectures.utah.edu/_documents/a-toz/s/sen86.pdf $>$. Acesso em 19 Nov. 2014.

SHECAIRA, Sérgio Salomão. Criminologia. 3. ed. rev. atual. e ampl. São Paulo: Editora Revista dos Tribunais, 2011.

SHECAIRA, Sérgio Salomão; CORRÊA JUNIOR, Alceu. Teoria da pena: finalidades, direito positivo, jurisprudência e outros estudos de ciência criminal. São Paulo: Editora Revista dos Tribunais, 2002.

SIECKMANN, Jan-R. Los derechos fundamentales como principios. Trad. Daniel Oliver-Lalana. In: SIECKMANN, Jan-R. (ed.). La teoría principialista de los derechos fundamentales: estudios sobre la teoría de los derechos fundamentales de Robert Alexy. Madrid: Marcial Pons, 2011

. Problemas de la teoría principialista de los derechos fundamentales. Trad. Daniel Oliver-Lalana. In: CLÉRICO, Laura; SIECKMANN, Jan-R.; OLIVER-LALANA, Daniel (coord.). Derechos 
fundamentales, principios y argumentación: estudios sobre la teoría jurídica de Robert Alexy. Granada: Editorial Comares, 2011.

SILVA SÁNCHEZ, Jesús-María. Introducción. In: SCHÜNEMANN, Bernd (org.). El sistema moderno del derecho penal: cuestiones fundamentales. Estudios en honor de Claus Roxin en su 50. ${ }^{\circ}$ aniversario. Madrid: Editorial Tecnos, 1984.

. La expansión del derecho penal: aspectos de la política criminal en las sociedades postindustriales. 2. ed. Madrid: Civitas, 2001.

. Observaciones sobre la relación entre derecho constitucional y derecho penal en España. Revista de Ciencias Jurídicas ¿Más derecho?, Buenos Aires, n. 2, 2001.

. Normas y acciones em derecho penal. Buenos Aires: Hammurabi, 2003.

. Nuevas tendencias político-criminales y actividad jurisprudencial del Tribunal Supremo Español. Revista Brasileira de Ciências Criminais, São Paulo: Editora Revista dos Tribunais, ano 4, n. 15, p. 39-50, jul.-set., 1996.

. Prólogo a la edición española. In: VON HIRSCH, Andrew; SEELMANN, Kurt; WOHLERS, Wolfgang. Límites al derecho penal: principios operativos en la fundamentación del castigo. Edição espanhola a cargo de Ricardo Robes Planas. Barcelona: Atelier, 2012.

- Sobre la interpretación teleológica en derecho penal. In: GARCÍA CONLLEDO, Miguel Díaz; GARCÍA AMADO, Juan Antonio. Estudios de filosofía del derecho penal. Bogotá: Universidad Externado de Colômbia, 2006.

. Una crítica a las doctrinas penales de la "lucha contra la impunidad" y del "derecho de la víctima al castigo del autor". Revista de Estudios de la Justicia, Ano 2009, n. 11.

SILVA, Virgílio Afonso da. A constitucionalização do direito: os direitos fundamentais nas relações entre particulares. São Paulo: Malheiros, 2008.

. Comparing the incommensurable: constitutional rights, balancing and rational decision. Oxford Journal of Legal Studies, Oxfor University Press, v. 31, n. 2, 2011.

. Direitos fundamentais: conteúdo essencial, restrições e eficácia. 2. ed. São Paulo: Malheiros, 2011.

. Interpretação conforme a constituição: entre a trivialidade e a centralização judicial. Revista Direito GV, v. 3, p. 191-210, 2006.

. Interpretação constitucional e sincretismo metodológico. In: SILVA, Virgílio (org.). Interpretação constitucional. São Paulo: Malheiros, 2007.

. O conteúdo essencial dos direitos fundamentais e a eficácia das normas constitucionais. Revista de Direito do Estado, v. 4, 2006.

. O proporcional e o razoável. Revista dos Tribunais, São Paulo: Editora Revista dos Tribunais, v. 798, p. 23-50, 2002.

. Ponderação e objetividade na interpretação constitucional. In: MACEDO JÚNIOR, Renato Porto; BARBIERI, Catarina Helena Cortada. Direito e interpretação: racionalidades e instituições. São Paulo: Saraiva, 2011.

. Princípios e regras: mitos e equívocos acerca de uma distinção. Revista Latino-Americana de Estudos Constitucionais, v. 1, 2003.

. Direitos fundamentais e relações entre particulares. Revista Direito GV, v. 1, n. 1., maio 2005. 
SILVEIRA, Renato de Mello Jorge (coord.). Crônicas franciscanas do mensalão: comentários pontuais do julgamento da ação penal $n^{\circ} 470$, junto ao STF, pelos professores de direito penal da Universidade de São Paulo. São Paulo: Quartier Latin, 2013.

. Tipificação criminal da violência de gênero: paternalismo legal ou moralismo penal? Boletim do Instituto Brasileiro de Ciências Criminais, São Paulo: IBCCRIM, n. 166, set. 2006.

. A mídia e a lei da mordaça. Boletim do Instituto Brasileiro de Ciências Criminais, São Paulo: São Paulo: IBCCRIM, n. 94, set. 2000.

. A segurança como critério de estipulação de crimes. In: GRECO, Luís; MARTINS, Antonio (org.). Direito Penal como crítica da pena: estudos em homenagem a Juarez Tavares por seu 70. aniversário em 2 de setembro de 2012. Madrid: Marcial Pons, 2012.

. Adequação social e direito penal. In: MENDES, Gilmar Ferreira; BOTTINI, Pierpaolo Cruz; PACELLI, Eugênio (coord.). Direito penal contemporâneo. São Paulo: Saraiva, 2011.

. Considerações penais sobre o acordo de leniência na realidade antitruste. In: PASCHOAL, Janaína Conceição; SILVEIRA, Renato de Mello Jorge. Livro homenagem a Miguel Reale Júnior. São Paulo: GZ Editoria, 2014.

. Crimes sexuais: bases críticas para a reforma do direito penal sexual. São Paulo: Quartier Latin, 2008.

. Direito penal econômico como direito penal de perigo. São Paulo: Editora Revista dos Tribunais, 2006.

. Direito penal supra-individual: interesses difusos. São Paulo: Editora Revista dos Tribunais, 2003.

. Fundamentos da adequação social em direito penal. São Paulo: Quartier Latin, 2010.

. Multiculturalism and criminal law: the brasilian case. Revue internationale de droit pénal, v. 82.

SILVEIRA, Renato de Mello Jorge; SAAD-DINIZ, Eduardo. Criminal compliance: os limites da cooperação normativa quanto à lavagem de dinheiro. Revista de Direito Bancário e do Mercado de Capitais, São Paulo: Editora Revista dos Tribunais, Ano 15, vol. 56, abr.-jun. 2012.

SIMON, Jonathan. Governing through crime: how the war on crime transformed American democracy and created a culture of fear. Nova York: Oxford University Press, 2007.

SOUZA, Luciano Anderson de. Direito penal econômico: fundamentos, limites e alternativas. São Paulo: Quartier Latin, 2012.

STEPHENS, Beth. The amorality of profit: transnational corporations and human rights. In: KINLEY, David. Human rights and corporations. Farnham: Ashgate Pubishing, 2009.

STRECK, Lenio Luiz. Do garantismo negativo ao garantismo positivo: a dupla face do princípio da proporcionalidade. JurisPoiesis, Rio de Janeiro: Universidade Estácio de Sá, ano 8, n. 7, jan. 2005.

SUBIJANA ZUNZUNEGUI, Ignacio José. El sistema penal: su legitimidad axiológica, contextual y teleológica. Eguzkilore, San Sebastián, n. 25, dez. 2011.

SUNSTEIN, Cass R. Democracy and the problem of free speech. New York: The Free Press, 1993.

. The laws of fear: beyond the precautionary principle. Cambridge: Cambridge University Press, 2005.

TAVARES, Juarez. A globalização e os problemas de segurança pública. In: HOLLENSTEINER, Stephan (org.). Estado e sociedade civil no processo de reformas no Brasil e na Alemanha. Rio de Janeiro: Lumen Juris, 2004. 
. Teoria do injusto penal. 2. ed. Belo Horizonte: Del Rey, 2002, p. 112.

TAYLOR, Charles. Hegel e a sociedade moderna. Trad. Luciana Pudenzi. São Paulo: Edições Loyola, 2005.

Hegel. Nova York: Cambridge University Press, 2005.

TERRADILLOS BASOCO, Juan M. La constitución penal. Los derechos de la libertad. In: TERRADILLOS BASOCO, Juan M. Sistema penal y estado de derecho. Lima: ARA Editores, 2010.

TEUBNER, Gunther. Altera pars audiatur: law in the collision of discourses. Trad. Klauz Ziegert e Ros Ziegert. In: RAWLINGS, Richard (ed.). Law, society and economy. Frankfurt: Oxford University Press, 1997.

. De collisione discursuum: communicative rationalities in law, morality, and politics. Cardozo Law Review, v. 17, 1995-1996.

. El derecho como sistema autopoiético. Trad. Carlos Gómez-Jara Díez. In: TEUBNER, Gunther. El derecho como sistema autopoiético de la sociedad global. Trad. Manuel Cancio Melía e Carlos Gómez-Jara Díez (ed.). Lima: ARA Editores, 2005.

. La constitucionalización de la sociedad global. Trad. Manuel Cancio Melía. In: TEUBNER, Gunther. El derecho como sistema autopoiético de la sociedad global. Trad. Manuel Cancio Melía e Carlos Gómez-Jara Díez (ed.). Lima: ARA Editores, 2005.

. Law as an autopoietic system. Trad. Anne Bankowska e Ruth Adler. Oxford, Cambridge: Blackwell, 1993.

. The anonymous matrix: human rights violations by "private" transnational actors. The Modern Law Review, Oxford: Blackwell Publishing, 2006, n. 69.

THORNHILL, Chris. Niklas Luhmann y la sociologia de la Constitución. Trad. Hugo Cadenas. In: CADENAS, Hugo; MASCAREÑO, Aldo; URQUIZA, Anahí (ed.). Niklas Luhmann y el legado universalista de su teoría: aportes para el análisis de la complejidad social contemporánea. Santiago: RIL Editores, 2012.

. Niklas Luhmann, Carl Schmitt and the modern form of the political. European Journal of Social Theory, 10, n. 4, 2007.

TIEDEMANN, Klaus. Derecho penal económico: introducción y parte general. Lima: Grijley, 2009.

TOMBS, Steve; WHYTE, Dave. Scrutinizing the powerful: crime, conteporary political economy, and critical social research. In: TOMBS, Steve; WHYTE, Dave. Unmasking the crimes of the powerful: scrutinizing States \& corporations. Nova York: Peter Lang Publishing, 2001.

TONRY, Michael. Can twenty-first century punishment policies be justified in principle? In: TONRY, Michael (ed.). Retributivism has a past: has it a future? Nova York: Oxford University Press, 2011.

TORRES NAFARRATE, Javier. Luhmann: la política como sistema. México, DF: Fondo de Cultura Económica, Universidad Iberoamericana, Universidad Nacional Autónoma de México, 2004.

TREVES, Renato. Giustizia e giudici nella società italiana. Bari: Editora Laterza, 1972.

TULLY, James. Strange multiplicity: constitutionalism in an age of diversity. Nova York: Cambridge University Press, 2006.

TURK, Austin T. Law as a weapon in social conflict. In: McCANN, Michael. Law and social movements. Aldershot: Ashgate Publishing, 2006. 
VEÇOSO, Fabia Fernandes Carvalho et al. A pesquisa em direito e as bases eletrônicas de julgados dos tribunais: matrizes de análise e aplicação no Supremo Tribunal Federal e no Superior Tribunal de Justiça. Revista de Estudos Empíricos em Direito, vol. 1, n. 1, jan. 2014.

VIEIRA, Oscar Vilhena. Supremocracia. Revista Direito GV, São Paulo, n. 4 (2), jul.-dez. 2008.

VILLAS BÔAS FILHO, Orlando. Teoria dos sistemas e o direito brasileiro. São Paulo: Saraiva, 2009.

VIVES ANTÓN, Tomás S. Fundamentos del sistema penal: acción significativa y derechos constitucionales. Valencia: Tirant lo Banch, 2011.

VOGEL, Joachim. Legislación penal y ciencia del derecho penal. (Reflexiones sobre una doctrina teóricodiscursiva de la legislación penal). Revista de Derecho Penal y Criminología, $2^{\mathrm{a}}$ Época, n. 11, 2003.

VOLTAIRE. Comentario sobre el libro "De los delitos y de las penas" por um abogado de provincias. Trad. Juan Antonio de las Casas. Madrid: Alianza Editorial, 2002.

VON HIRSCH, Andrew. Proportionality in the philosophy of punishment. Crime and Justice, Chicago: The University of Chicago Press, vol. 16, 1992.

VON HIRSCH, Andrew; SEELMANN, Kurt; WOHLERS, Wolfgang. Introducción. ¿Qué son los "mediating principles"? Trad. Ricardo Robles Planas. In: VON HIRSCH, Andrew; SEELMANN, Kurt; WOHLERS, Wolfgang. Límites al derecho penal: principios operativos en la fundamentación del castigo. Edição espanhola a cargo de Ricardo Robes Planas. Barcelona: Atelier, 2012.

VORMBAUM, Thomas; BOHLANDER, Michael. A modern history of german criminal law. Trad. Margaret Hiley. Heidelberg: Springer, Volkswagen Stiftung, 2014.

WELZEL, Hans. El nuevo sistema del derecho penal: una introducción a la doctrina de la acción finalista. Trad, José Cerezo Mir. Buenos Aires: Editorial B de F, 2004.

WINDLESHAM, Lord. Politics, punishment, and populism. Nova York, Oxford: Oxford University Press, 1998.

WOHLERS, Wolfgang. Derecho penal como ultima ratio. ¿Principio fundamental del derecho penal de um Estado de Derecho o principio sin un contenido expressivo propio? Trad. Núria Pastor Muñoz. In: VON HIRSCH, Andrew; SEELMANN, Kurt; WOHLERS, Wolfgang. Limites al derecho penal: principios operativos en la fundamentación del castigo. Edição espanhola a cargo de Ricardo Robes Planas. Barcelona: Atelier, 2012.

WOLTER, Jürgen. Estudios sobre la dogmática y la ordenación de las causas materiales de exclusión, sobreseimiento del proceso, de la renuncia de la pena y de la atenuación de la misma. Estructuras de un sistema integral que abarque el delito, el proceso penal u la determinación de la pena. Trad. Guillermo Benlloch Petit. In: WOLTER, Jürgen; FREUND, Georg. El sistema integral del derecho penal: delito, determinación de la pena y processo penal. Madrid: Marcial Pons, 2004.

. Problemas político-criminales y jurídico-constitucionales de uns sistema internacional del derecho penal. In: SILVA SÁNCHEZ, Jesús-María (ed.). Política criminal y nuevo derecho penal: libro homenaje a Claus Roxin. Barcelona: José María Bosch Editor, 1997.

YANCARELLI, Lucas. Enfoque constitucional de la acción penal y el principio de oportunidad. Revista de Derecho Penal y Procesal, n. 5, 2013.

ZACZYK, Rainer. "Ha matado, entonces debe morir". Kant y el derecho penal. Trad. Miguel Polaino-Orts. In: ZACZYK, Rainer. Libertad, derecho y fundamentación de la pena. Eduardo Montealegre Lynett, Nathalia Bautista Pizarro, José Antonio Caro John e Miguel Polaino-Orts (comp.). Bogotá: Universidad Externado de Colombia, 2010. 
. El Estado y la pena: consideraciones sobre el denominado "ejemplo de la isla" en La Metafísica de las Costumbres de Kant. Trad. Jorge Fernando Perdomo Torres. In: ZACZYK, Rainer. Libertad, derecho y fundamentación de la pena. Eduardo Montealegre Lynett, Nathalia Bautista Pizarro, José Antonio Caro John e Miguel Polaino-Orts (comp.). Bogotá: Universidad Externado de Colombia, 2010.

ZAFFARONI, Eugenio Raúl. Tratado de derecho penal, parte general II. Buenos Aires: Ediar, 1987.

ZAFFARONI, Eugenio Raúl; ALAGIA, Alejandro; SLOKAR, Alejandro. Derecho penal: parte general. 2. ed. Buenos Aires: Ediar, 2002.

ZAGREBELSKY, Gustavo. El derecho dúctil. Trad. Marina Gascón. Madrid: Editorial Trotta, Comunidad de Madrir, 1995.

ZUÑIGA RODRÍGUEZ, Laura. Relaciones entre derecho penal y derecho administrativo sancionador. ¿Hacia una "administrativización" del derecho penal o una "penalización" del derecho administrativo sancionador? In: NIETO MARTIN, Adán (coord..).Homenaje al Dr. Marino Barbero Santos: In memoriam, vol. 1. Cuenca: Ediciones de la Universidad de Castilla-La Mancha, Ediciones Universidad Salamanca, 2001. 